\title{
Towards understanding the unusual Indian monsoon in 2009
}

\author{
P A Francis ${ }^{1, *}$ and Sulochana Gadgil ${ }^{2, * *}$ \\ ${ }^{1}$ Indian National Centre for Ocean Information Services, Ministry of Earth Science, P. B. No. 21, \\ Ocean Valley, IDA Jeedimethla P. O., Hyderabad 500 055, India. \\ ${ }^{2}$ Centre for Atmospheric and Oceanic Sciences, Indian Institute of Science, Bangalore 560 012, India. \\ *e-mail: francis@incois.gov.in \\ **e-mail: sulo@caos.iisc.ernet.in
}

The Indian summer monsoon season of 2009 commenced with a massive deficit in all-India rainfall of $48 \%$ of the average rainfall in June. The all-India rainfall in July was close to the normal but that in August was deficit by 27\%. In this paper, we first focus on June 2009, elucidating the special features and attempting to identify the factors that could have led to the large deficit in rainfall. In June 2009, the phase of the two important modes, viz., El Niño and Southern Oscillation (ENSO) and the equatorial Indian Ocean Oscillation (EQUINOO) was unfavourable. Also, the eastern equatorial Indian Ocean (EEIO) was warmer than in other years and much warmer than the Bay. In almost all the years, the opposite is true, i.e., the Bay is warmer than EEIO in June. It appears that this SST gradient gave an edge to the tropical convergence zone over the eastern equatorial Indian Ocean, in competition with the organized convection over the Bay. Thus, convection was not sustained for more than three or four days over the Bay and no northward propagations occurred. We suggest that the reversal of the sea surface temperature (SST) gradient between the Bay of Bengal and EEIO, played a critical role in the rainfall deficit over the Bay and hence the Indian region. We also suggest that suppression of convection over EEIO in association with the El Niño led to a positive phase of EQUINOO in July and hence revival of the monsoon despite the El Niño. It appears that the transition to a negative phase of EQUINOO in August and the associated large deficit in monsoon rainfall can also be attributed to the El Niño.

\section{Introduction}

In 2009, after an early onset over Kerala on 23 May, the advance of monsoon over the Indian region was delayed by about two weeks and the monsoon rainfall was restricted to the west coast and southern peninsula until 24 June (figure 1a). This resulted in a massive deficit in the allIndia rainfall of $54 \%$ of the long term average for this period. The all-India rainfall deficit for the month of June 2009 (48\%) was close to the highest recorded deficit in June rainfall since 1871 (i.e., $50 \%$ in 1926). There was a partial recovery in July with the all-India rainfall being $95 \%$ of the mean. However, the all India rainfall deficit for the month of August was 27\%. There was a large deficit (21\%) rainfall in September as well. Thus the summer monsoon season (JuneSeptember) turned out to be one of the five most severe droughts during 1876-2009 with the Indian summer monsoon rainfall (ISMR) in deficit by $23 \%$. The impact of this large deficit in monsoon rainfall was felt across the entire country, not only by the farmers but also the urban population who felt the pinch in rising prices and water and power shortages.

Keywords. Indian summer monsoon; equatorial Indian Ocean Oscillation; El Niño; SST gradient; tropical convergence zone; drought; climate; coupled systems; monsoons. 


\section{भारत मौसम विज्ञान विभाग \\ INDIA METEOROLOGICAL DEPARTMENT}

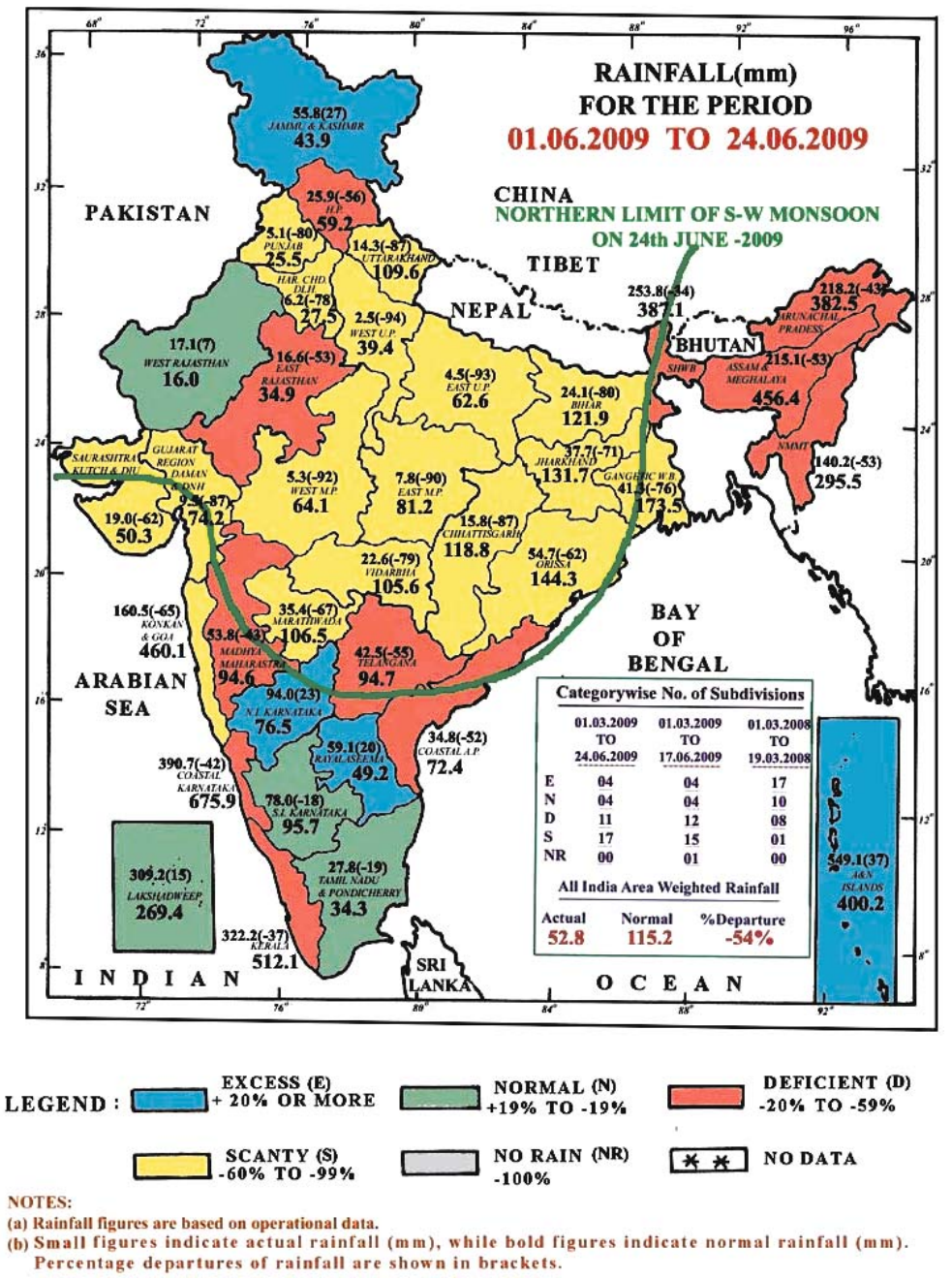

Figure 1(a). Actual rainfall ( $\mathrm{mm}$ ) for the period 1-24 June 2009 for each of the meteorological subdivisions. Climatological rainfall $(\mathrm{mm})$ is also shown in bold. Source: www.imdpune.gov.in. Northern limit of the south-west monsoon as on 24 June 2009 is shown as green curve.

A large deficit in the rainfall during the summer monsoon was not expected from the predictions generated by the leading centres in the world using general circulation models of the atmosphere or of the coupled ocean-atmosphere system. Almost all the models predicted above average rainfall for June-July-August (JJA) over most of the Indian region (Nanjundiah 2009) which is the opposite of what was experienced (figure 1b). This is not surprising because, despite significant improvement in the models and observations, the simulation and prediction of the Indian summer monsoon remains a challenge even today (Gadgil et al 2005; Wang et al 2008). As in 2009, the models generally fail in anticipating the extremes of summer monsoon rainfall, i.e., droughts and excess rainfall seasons (defined as seasons with the all-India
June-September rainfall less than $90 \%$ and more than $110 \%$ of the long term average, respectively). So for assessing the chance of a drought, we have to rely either on past history or on the links with phenomena which can be predicted, such as El Niño and Southern Oscillation (ENSO).

Clearly, the most important facet of the season of 2009 is the massive deficit in rainfall in June 2009. It is important to understand why the monsoon rainfall was so poor in June. Krishnamurti et al (2009) have shown that during the dry spell in June, when the advance of the monsoon was delayed, a west Asian blocking high occurred with a strong northerly component of air over west Asia. The associated northerly descending air steadily brought very dry west Asian desert air towards central India. They further showed that 


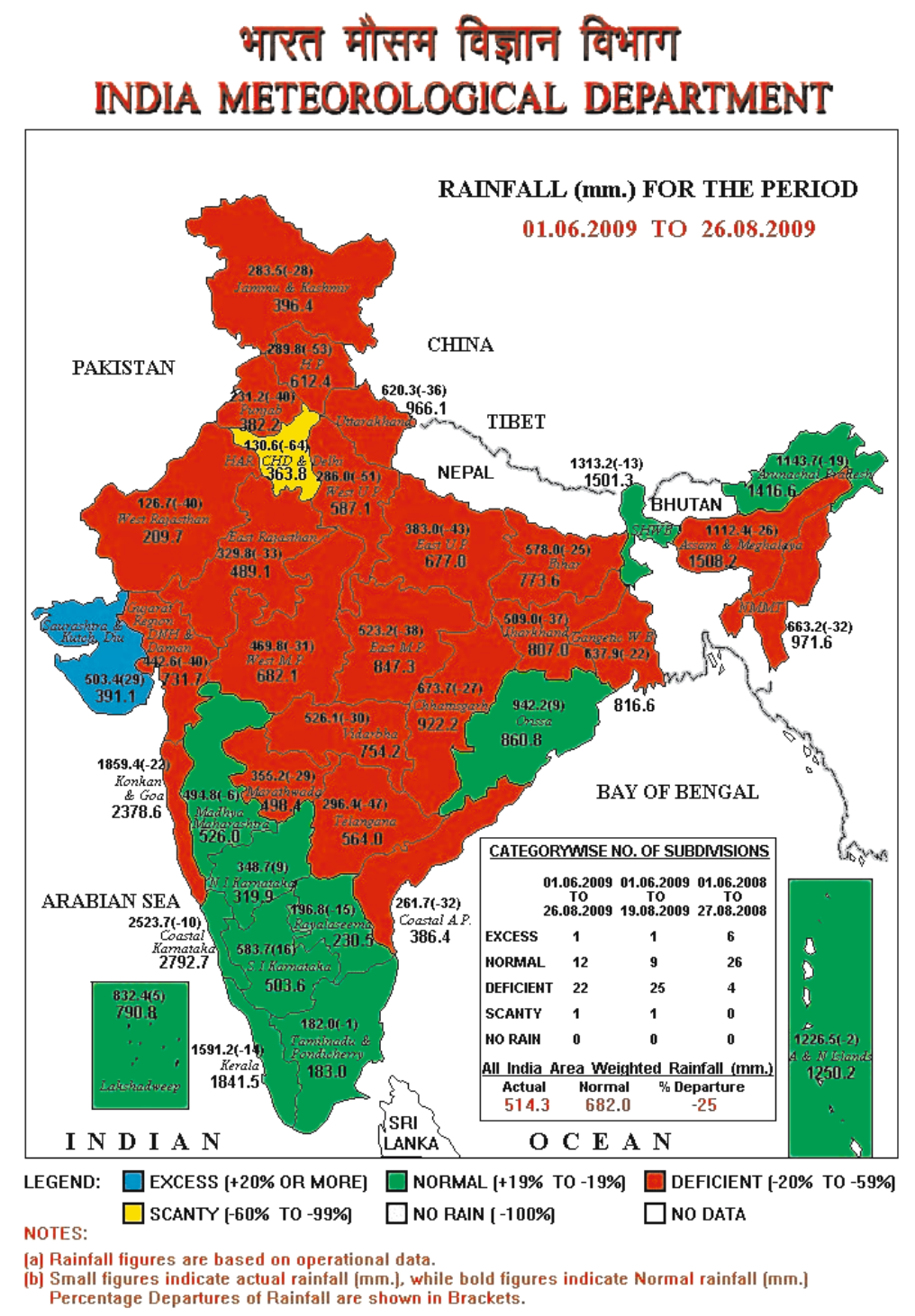

Figure 1(b). Actual rainfall (mm) for the period 1 June-26 August, 2009 for each of the meteorological subdivisions. Climatological rainfall $(\mathrm{mm})$ is also shown in bold. Source: www.imdpune.gov.in.

this feature was a robust indicator of several dry spells during 1966 to 2002. This is consistent with Bhat's (2006) study for July 2002, for which the deficit in rainfall was even larger than that of June 2009, which showed the presence of a persistent and strong inversion near $800 \mathrm{hPa}$ and advection of dry air from over the deserts around the eastern Arabian Sea above that level, instead of marine air from across the equator. The important role played by the mid-latitude circulation was first pointed out by Ramaswamy (1958), who suggested that elongation of mid-tropospheric westerly troughs into India was associated with dry spells/breaks. Raman and Rao (1981) suggested that an intense west Asian blocking ridge was the initiator of prolonged breaks in several seasons of severe droughts. Pointing out that most of the earlier investigations involved case studies which consider composites of breaks or active periods, Kripalani et al (1997) considered correlations of the anomalies of the geopotential height with rainfall over the Indian region. They showed that large scale ridging in mid-latitudes favours enhanced precipitation over northern India. Ding and Wang (2007)'s study also suggests that 'once the anomalous high is generated over central Asia, it can excite convection over the northern Indian summer monsoon region'. The discrepancy between their results and the results of earlier studies could be because there are many occasions on which the blocking high occurs in the absence of a break. Thus it appears that while it is widely accepted that interaction between the mid-latitudinal circulation and intraseasonal variation of the monsoon is important, there is no consensus as yet on whether it can be considered as one of the factors leading to dry 
spells or breaks. The impact of the Asian blocking ridge has also been considered to be important on the seasonal scale. Raman and Rao (1981) noted the existence of two upper-tropospheric blocking ridges situated over the north Caspian Sea and eastern Siberia during breaks in the severe drought years. Krishnamurthi et al (1989) had suggested that such a blocking high was one of the important factors leading to the drought of 1987. Rajeevan (1993) had pointed out that the anomaly pattern for seven droughts between 1965 and 1982 was characterized by a cyclonic circulation at 200 hpa over central Asia and large-scale intrusion of dry westerlies into the Indian region which were first seen in April. Joseph and Srinivasan (1999) showed that many droughts were associated with the spatial phase of the Rossby wave at $200 \mathrm{hpa}$ in May being characterized by a cyclonic vortex over northwest India with southerlies prominent over a large part of the Indian region north of $20^{\circ} \mathrm{N}$. However, while the phase of the Rossby wave characteristic of droughts occurs in May of several drought years it is not always followed by a drought (e.g., 1997) and not all droughts are preceded by such a pattern in May (e.g., 1985) (Srinivasan, personal communication). Thus on the intraseasonal and seasonal scales it is not yet clear whether west Asian blocking during the summer is a cause of deficit monsoon rainfall. This problem requires further investigations. It is important to note that most of the droughts considered in these studies happen to be El Niño years. In fact, Yasunari (1987) has shown that the Asian blocking high is a feature of the developing stage of the El Niño. Here we explore the possibility of understanding the variation of rainfall during JJA 2009 in terms of the important facets of the tropical Indian and Pacific ocean-atmosphere system.

The strong link of the Indian summer monsoon rainfall with ENSO manifested as a high propensity of droughts during the warm phase of ENSO (El Niño) and of excess rainfall during La Niña, the cold phase of ENSO (Sikka 1980; Pant and Parthasarathy 1981; Rasmusson and Carpenter 1983; Ihara et al 2007, etc.) is well known. Hence, it has also been suggested that the deficit rainfall in June 2009 was a consequence of the developing El Niño (http://www.cpc.ncep.noaa.gov). In addition to ENSO, Equatorial Indian Ocean Oscillation (EQUINOO) is also known to play a critical role in the interannual variation of Indian summer monsoon (Gadgil et al 2003, 2004; Ihara et al 2007). In June 2009, the phase of EQUINOO was also unfavourable. Thus the situation was similar to the recent drought of 2002 with both ENSO and EQUINOO being unfavourable. However, with stronger El Niño and more unfavourable EQUINOO in June 2002, the rainfall was normal. Hence, it appears that the deficit rainfall in June 2009 cannot be merely a consequence of the unfavourable phases of ENSO and EQUINOO (Francis and Gadgil 2009). Here we address the problem of understanding the variation of the all-India rainfall during June-August 2009.

We first elucidate the special features of June 2009 and attempt to identify factors that could have led to the huge deficit in all-India rainfall. We then try and understand the partial recovery of the monsoon in July and August. In the next section we describe the data analyzed and in section 3 , we summarize some basic features of the Indian summer monsoon and our present understanding in terms of the links of the interannual variation of the monsoon with phenomena such as ENSO, which are relevant for our analysis of the monsoon of 2009. We then focus on June 2009 in section 4 , with a discussion of the special features in section 4.1, considering the role of ENSO in 4.2 and identifying an additional unfavourable factor which could have played a role in June 2009 in section 4.3. The monsoon during July and August 2009 is considered in section 5 and summary and concluding remarks are included in the last section.

\section{Data and methodology}

In the present study, we use the outgoing longwave radiation (OLR) measured by the NOAA satellites, archived at http://www.cdc.noaa.gov (Liebmann and Smith 1996) as a proxy for the tropical convection. Data on the surface zonal wind are obtained from the NCEP reanalysis (Kalney et al 1996), which is also available at http://www. cdc.noaa.gov. The sea surface temperature (SST) measured by TMI sensor of Tropical Rainfall Measurement Mission (TRMM) satellite (available at ftp://ftp.ssmi.com/tmi) as well as the NOAA optical interpolated SST (Reynolds et al 2002), available at http://cdc.noaa.gov, are analyzed. We use 3-day running mean of TMI SST and weekly and monthly Reynolds SST data. We also use the all-India rainfall data (Prathasarathy et al 1994) from the website of the Indian Institute of Tropical Meteorology at http:// www.tropmet.res.in. and India Meteorological Department (http://www.imd.gov.in).

We use an ENSO index which is based on the normalized SST anomaly of the central Pacific (Nino 3.4, obtained from http:// www.cpc.noaa.gov). The Nino 3.4 SST anomaly is used rather than the SST anomaly of the east Pacific (Nino 3), since the magnitude of the correlation with the Indian summer monsoon rainfall 
(ISMR) is somewhat higher for the former (Gadgil et al 2004). The sign of the index is chosen so that positive values imply the cold phase, which is favourable for the monsoon. EQWIN, the index of EQUINOO is defined as the negative of the normalized zonal wind anomaly over the central equatorial Indian Ocean, i.e., $60-90^{\circ} \mathrm{E}, 2.5^{\circ} \mathrm{S}-2.5^{\circ} \mathrm{N}$ (Gadgil et al 2004). Thus positive values of EQWIN imply a phase of EQUINOO which is favourable for the monsoon. For generating anomalies and correlations, we have chosen the period 1982-2009 during which both the NOAA OLR and Reynolds SST data are available. Since TMI data are available for a relatively short period (1998-2009), we do not compute the SST anomaly for the TMI SST data.

\section{The Indian monsoon and its interannual variation}

The monsoon is a manifestation of the seasonal variation of the tropical convergence zone (TCZ) in response to the seasonal variation of the solar radiation. The large-scale rainfall over the Indian region during the summer monsoon is associated with a TCZ, which appears as a prominent zonal cloud band in satellite imagery. In most of the years, this continental TCZ (CTCZ) is established over the Indian monsoon zone north of about $20^{\circ} \mathrm{N}$ by July. The CTCZ generally extends eastward from the monsoon zone to the head of the Bay of Bengal and often even farther eastwards. Most of the cloud systems that give rainfall over the Indian region are generated over the warm oceans around the subcontinent and propagate onto the subcontinent. The onset phase of the summer monsoon commences with the onset of the monsoon over Kerala in late May/early June and comprises northward movement of the TCZ from the equatorial Indian Ocean in one or more surges (Ding and Sikka 2006 and references therein). In satellite imagery, these are seen as northward propagations of cloud bands stretching from the Arabian Sea across the Indian region to the Bay of Bengal (Sikka and Gadgil 1980). The onset phase also involves synoptic systems such as lows and depressions moving westward from the Bay across the Indian monsoon zone towards Rajasthan (Ding and Sikka 2006 and references therein). Such westward propagations occur throughout the monsoon season and are critical for the large-scale rainfall over the monsoon zone. A series of northward propagations, similar to the ones in the onset phase occur at intervals of 2-6 weeks throughout the summer monsoon season (Sikka and Gadgil 1980; Ding and Sikka 2006 and references therein). These northward propagations and propagations of systems generated over the Bay of Bengal and the Arabian Sea onto the Indian region are critical for maintaining the CTCZ. Thus, although the part of the CTCZ which is over the landmass is relevant for the large scale monsoon rainfall over the Indian region, the part that overlies the Bay of Bengal (and also that over the Arabian Sea) as well as the TCZ over the equatorial Indian Ocean are critical for the maintenance of the TCZ over land. The variability of the CTCZ and the large scale monsoon rainfall is, therefore, linked with the variability of convection/precipitation over the surrounding seas and the equatorial Indian Ocean.

The mean monthly sea surface temperature (SST) patterns during the summer monsoon are shown in figure 2(a). It is seen that there is a warm belt over the equatorial Indian Ocean with a maximum SST over $60^{\circ}-100^{\circ} \mathrm{E}$ around the equator. The relationship of weekly OLR with SST for all the $2.5^{\circ} \times 2.5^{\circ}$ grids over the equatorial Indian Ocean $\left(50^{\circ}-100^{\circ} \mathrm{E}, 5^{\circ} \mathrm{S}-5^{\circ} \mathrm{N}\right)$ for JJA during 1998 2009 is shown in figure 2(b). It is seen that when SST is above the threshold for organized convection $\left(28^{\circ} \mathrm{C}\right.$, Gadgil et al 1984; Graham and Barnett 1987), there is a high propensity of convection with a large number of grid points with OLR $<200 \mathrm{~W} / \mathrm{m}^{2}$; whereas when SST is below the threshold, there are hardly any such grids implying that deep convection is absent. However, for SST higher than the threshold, there is a very large spread from low OLR values indicating deep convection to high OLR values indicating clear skies. Whether convection occurs or not over such warm oceans is determined by the dynamics, i.e., occurrence of low level convergence (Graham and Barnett 1987). It is seen from figure 2(a) that climatologically a large part of the equatorial Indian Ocean, the Bay of Bengal and eastern Arabian Sea are above the threshold throughout the summer monsoon. Hence, favourable dynamical conditions are expected to lead to the occurrence of organized convection/TCZ. The mean monthly OLR patterns depicted in figure 2(c) show that climatologically, the monthly OLR is less than $220 \mathrm{~W} / \mathrm{m}^{2}$ (indicating the occurrence of convection) over a large part of the warm equatorial belt $\left(60^{\circ}-100^{\circ} \mathrm{E}\right)$. This is a manifestation of a special feature of the Indian longitudes, viz., the occurrence of the TCZ over the equatorial Indian Ocean intermittently throughout the summer monsoon leading to a bimodal distribution of the number of convective days with latitude (Sikka and Gadgil 1980). The role played by the northward propagations of this oceanic TCZ onto the Indian region in maintaining the CTCZ has already been pointed out.

Although the oceanic TCZ contributes to the CTCZ by northward propagations, the relationship of the CTCZ and the TCZ is complex and 

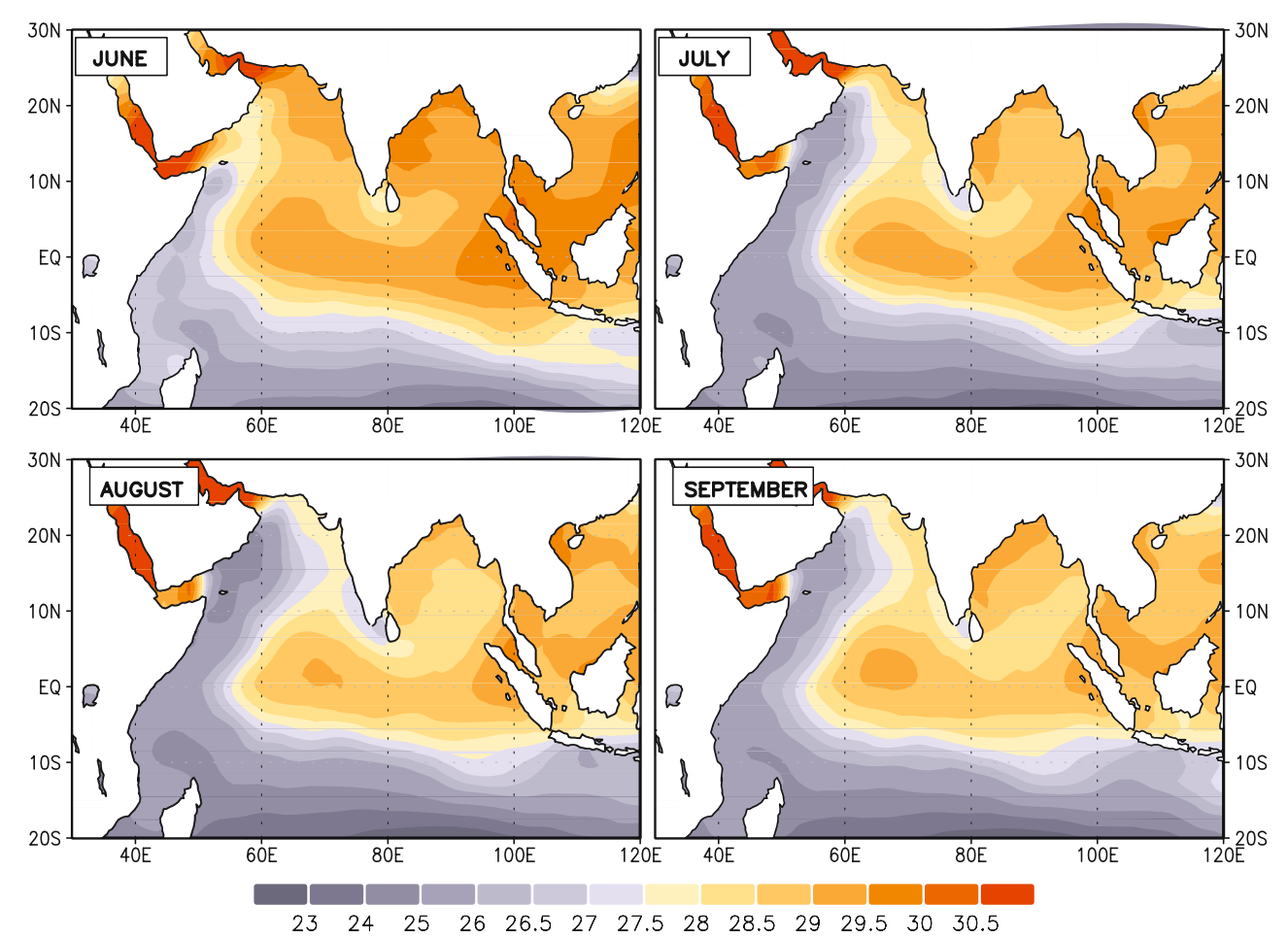

Figure 2(a). The mean monthly SST $\left({ }^{\circ} \mathrm{C}\right)$ patterns for June, July, August and September.

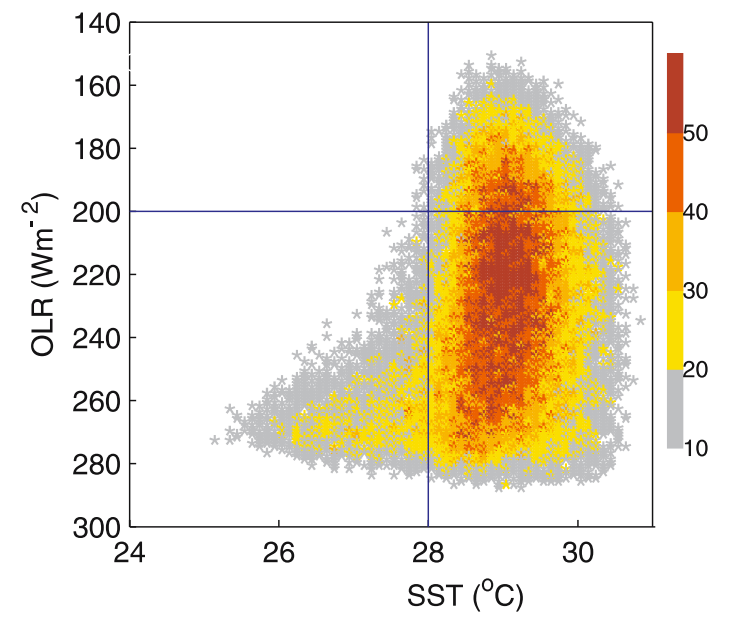

Figure 2(b). Scatter plot showing the weekly Reynolds SST $\left({ }^{\circ} \mathrm{C}\right)$ and OLR $\left(\mathrm{Wm}^{-2}\right)$ for each 2.5 degree grid of the equatorial Indian Ocean $\left(50^{\circ}-100^{\circ} \mathrm{E}, 5^{\circ} \mathrm{S}-5^{\circ} \mathrm{N}\right)$ during JJA 1998-2007.

the occurrence of the TCZ over the equatorial Indian Ocean is not always favourable for the CTCZ. Over the longitudes of Indian subcontinent, the oceanic TCZ also competes with the CTCZ (because each can come under the descending limb of the other), with weak spells of the monsoon TCZ generally coinciding with active spells of the oceanic TCZ and vice-versa (Sikka and Gadgil 1980). It turns out that in the summer monsoon/ JJA, convection over the eastern equatorial Ocean $\left(\mathrm{EEIO}, 90^{\circ}-110^{\circ} \mathrm{E}, 10^{\circ} \mathrm{S}-\mathrm{EQ}\right)$ and over the central equatorial Indian Ocean (CEIO, $70^{\circ}-90^{\circ} \mathrm{E}, 5^{\circ} \mathrm{S}-$ $5^{\circ} \mathrm{N}$ ) is unfavourable while that over the western equatorial Indian ocean (WEIO, $50^{\circ}-70^{\circ} \mathrm{E}, 10^{\circ} \mathrm{S}-$ $10^{\circ} \mathrm{N}$ ) is favourable for rainfall over the Indian region. These relationships are illustrated for July in figure 3 in which the correlation of the monthly OLR with the monthly OLR averaged over these regions is depicted. Consistent with this, the composite OLR anomaly patterns for monsoon breaks shows enhancement of convection over a region extending from EEIO to central equatorial Indian Ocean, while that for active spells convection is suppressed over this region (Gadgil and Joseph 2003; Rajeevan et al 2008, 2010).

On the interannual scale, the strong link of the Indian summer monsoon rainfall (ISMR) to ENSO with a higher propensity of droughts (excess rainfall seasons) during El Niño (La Niña) is well known (Sikka 1980; Pant and Parthasarathy 1981; Rasmusson and Carpenter 1983, etc.). A detailed investigation by Ihara et al (2007) of the monsoon ENSO relationship for the period 1880-1998 has shown that the correlation is highly significant and explains over $32 \%$ of the variance of the Indian summer monsoon rainfall. However, during the strongest El Niño event of the century in 1997, the ISMR was higher than the long term mean whereas a severe drought occurred in the summer monsoon season of 2002, which was characterized by a much weaker El Niño than that of 1997. The impact of El Niño on the monsoon has been shown 

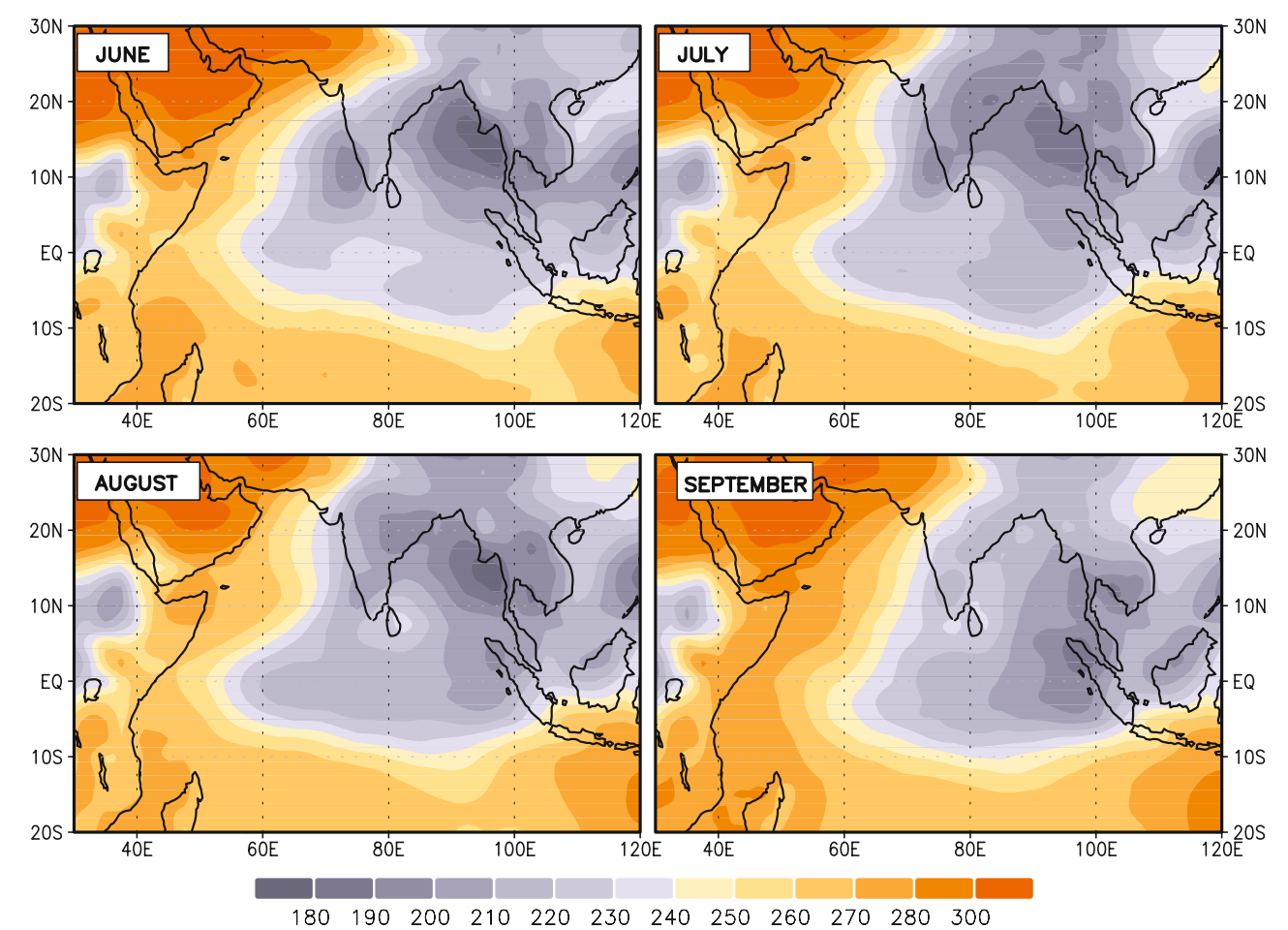

Figure 2(c). Mean monthly OLR $\left(\mathrm{Wm}^{-2}\right)$ for June, July, August and September.

to be related to the pattern of SST anomalies over the Pacific (Krishna Kumar et al 2006) and to the nature of the evolution of the El Niño in the seasons preceding the summer monsoon (Ihara et al 2008). Krishna Kumar et al (2006) suggested that El Niño events with the warmest SST anomalies in the central equatorial Pacific (such as 2002) are more effective in focusing drought-producing subsidence over India than events with the warmest SST over the eastern equatorial Pacific (such as 1997).

The nature of the impact of ENSO can be gleaned from figure $4(\mathrm{a}, \mathrm{c})$ in which the correlation of monthly OLR with the ENSO index is depicted for the peak monsoon months of July and August. The El Niño, characterized by the enhancement of convection over the equatorial central and east Pacific, is associated with suppression of convection over the Indian region, the Arabian Sea and the entire equatorial Indian Ocean belt. The suppression is seen to be larger over the eastern equatorial Indian Ocean than that over the western equatorial Indian Ocean.

Recent studies have shown that in addition to ENSO, the equatorial Indian Ocean Oscillation (EQUINOO) plays an important role in the interannual variation of the Indian summer monsoon rainfall (ISMR). The convection over EEIO is negatively correlated with that over WEIO with a correlation coefficient of -0.31 , which is significant at 0.05 level. EQUINOO is the oscillation between a state in which convection over WEIO is enhanced and that over EEIO is suppressed and one in which the convection anomalies are of the opposite sign (Gadgil et al 2004). The positive phase of the EQUINOO, which is characterized by enhanced convection over the WEIO and suppressed convection over the EEIO, is favourable for the monsoon. During positive phases of EQUINOO, the anomaly of the zonal wind over CEIO is easterly. Note that climatologically, during July-September, the OLR over EEIO is lower than that over WEIO and the zonal wind over the central equatorial Indian Ocean $\left(\mathrm{CEIO}, 60^{\circ}-90^{\circ} \mathrm{E}, 2.5^{\circ} \mathrm{S}-2.5^{\circ} \mathrm{N}\right)$ is westerly. Gadgil et al $(2003,2004)$ showed that, in addition to ENSO, EQUINOO also plays an important role in determining the interannual variation of the Indian summer monsoon rainfall. For the period 1958-2003 they showed that each drought (excess rainfall season) is associated with unfavourable (favourable) phases of either ENSO or EQUINOO, or both. The worst droughts are associated with unfavourable phases of both modes. Gadgil et al (2004) further showed that there is a strong relationship between the extremes of ISMR and a composite index of ENSO and EQUINOO with all the droughts characterized by low values of this index and all excess monsoon seasons, high values. Ihara et al (2007) investigated the relationship of the variation of the monsoon with ENSO, EQUINOO and IOD, using data for a much longer period (from 1881 to 1998) than that used by Gadgil et al (2004) and showed that the linear reconstruction 

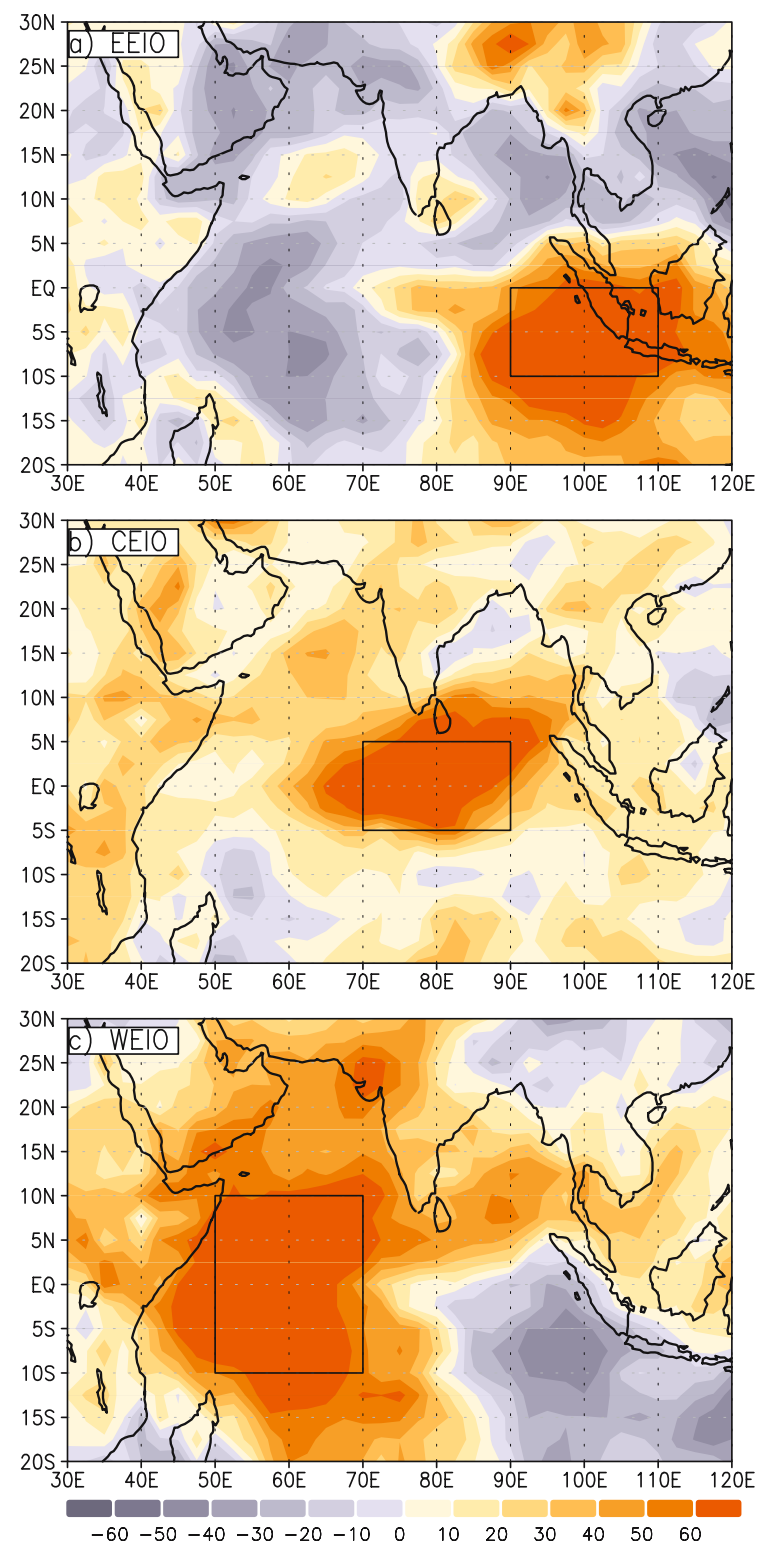

Figure 3. The correlation of monthly OLR (multiplied by 100) with the monthly OLR averaged over (a) EEIO $\left(90^{\circ}-110^{\circ} \mathrm{E}, 10^{\circ} \mathrm{S}-0\right)$, (b) $\mathrm{CEIO}\left(70^{\circ}-90^{\circ} \mathrm{E}, 5^{\circ} \mathrm{S}-5^{\circ} \mathrm{N}\right)$, and (c) WEIO $\left(50^{\circ}-70^{\circ} \mathrm{E}, 10^{\circ} \mathrm{S}-10^{\circ} \mathrm{N}\right)$ for July.

of ISMR on the basis of a multiple regression with their ENSO index and EQWIN better specifies the ISMR, than the regression with only the ENSO index. However, it is important to note that these studies reveal association of the ISMR anomalies with phases of these modes and will be of value for prediction of ISMR only if the modes can be predicted ahead of the season.

The negative phase of EQWIN is associated with suppression of convection over the Indian region and the western equatorial Indian Ocean (figure 4b, d). The intriguing behaviour of 1997 vs. 2002 (which was attributed to the warm SST anomaly being larger over the central equatorial Pacific in 2002 by Krishna Kumar et al 2006) can also be understood in terms of ENSO and EQUINOO. When both ENSO and EQUINOO are unfavourable (such as in 2002), the convection over the equatorial Indian Ocean as well as the surrounding seas is suppressed. Since convection over these oceanic regions is the life-line of the monsoon, it is not surprising that convection over the Indian region is highly suppressed and large deficits occur in the Indian summer monsoon rainfall when both the modes are unfavourable. However, if only ENSO is unfavourable, such as in the season of 1997 in which a severe El Niño occurred, the adverse impact of the El Niño can be mitigated by a strong positive EQUINOO (which was the case in 1997) and the monsoon rainfall was close to normal. As in 2002, ENSO and EQUINOO were both unfavourable in June 2009, but the magnitudes of the ENSO index and EQWIN were not as large as during any month of the summer monsoon of 2002 (figure 5). Yet the deficit in June 2009 in all-India rainfall is comparable to that in July 2002. We need to understand why.

\section{The monsoon in June 2009}

\subsection{Important facets}

Since the most important feature of the onset phase in June is the northward propagation of the TCZ from the equatorial regions, we consider first the observed variation of zones of convection (i.e., low OLR) with latitude over the Indian longitudes during June-August 2009. The variation of the low OLR region at $85^{\circ} \mathrm{E}$ in 2009 is compared with that during 2008 and 2002 in figure 6. Whereas in June 2002 and 2008, a northward propagation commencing in early June and lasting for about two weeks is seen, no such propagation occurred until the last week of June 2009. In this period, no propagations were seen over $70^{\circ} \mathrm{E}$ and $80^{\circ} \mathrm{E}$ either. It is seen that during 1-24 June 2009, although organized convection did occur over the Bay, it was not sustained for more than 3-4 days. During this period, convection occurred frequently in the $0^{\circ}-10^{\circ} \mathrm{S}$ belt. For example, convection was generated over the Bay and a TCZ appeared around $10^{\circ} \mathrm{N}$ on 30 May, soon after the cyclone Aila disappeared (figure 7). However, on 1st of June, a cloud band was seen over the equatorial Indian Ocean and the convection over the Bay and the TCZ across the Indian region disappeared. Convection over the central Bay revived on 4 June, an active TCZ was seen across the Indian peninsula on 6 June, and the Indian region received good rainfall during 5-7 June. But the convection over the Bay disappeared again by the 8 June. Thus during 1-24 June 2009, the life span of convective events over the Bay was never longer 

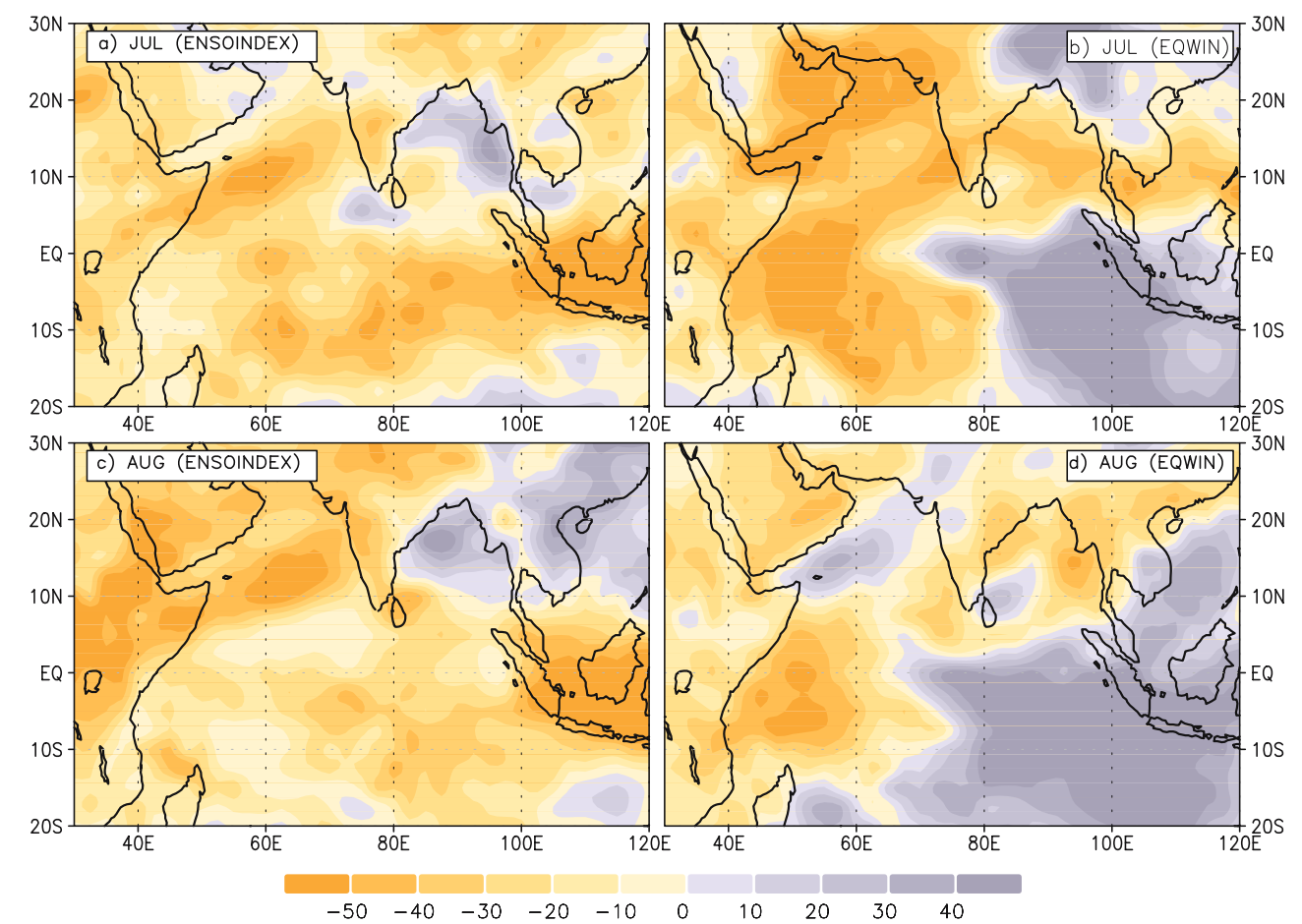

Figure 4. The correlation (multiplied by 100) of (a) the ENSO index with OLR for the month of July, (b) the EQWIN with OLR for the month of July, (c) the ENSO index with OLR for the month of August, and (d) the EQWIN with OLR for the month of August.

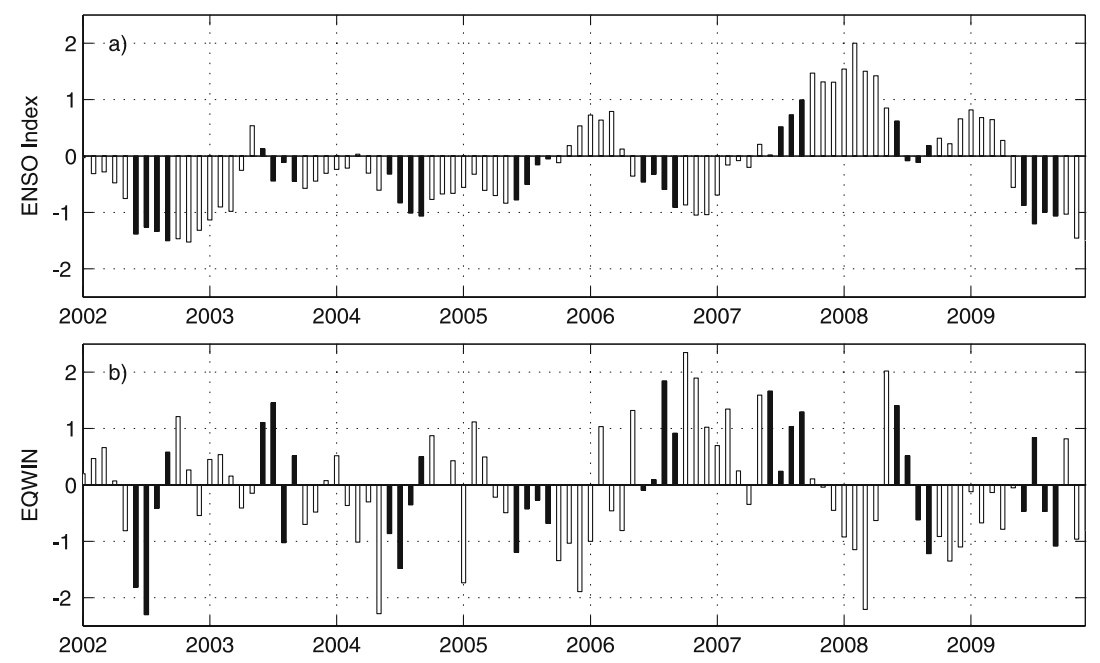

Figure 5. Observed variation of the monthly ENSO index and EQWIN during 2002-2009; the summer monsoon months are shown as solid bars.

than about 3-4 days and no northward movement was observed. No low pressure systems were generated over the head of the Bay and the westward propagation across the monsoon zone, which is characteristic of the onset phase of the monsoon, did not occur. Hence the monsoon did not advance beyond the southern peninsula and there was hardly any rainfall over the monsoon zone until 24 June. Finally, northward propagation of the equatorial TCZ occurred towards the end of June and convection was sustained thereafter for several days, albeit at a more southerly latitude than in most of the years such as 2008 and 2002 (figure 6).

The correlation of pentad mean OLR with the pentad OLR averaged over the Bay (figure 8) shows that on the subseasonal scale, suppression of convection over the Bay (as in June 2009) is associated with the enhancement of convection over the equatorial Indian Ocean between $0^{\circ}-10^{\circ} \mathrm{S}$ and east of $80^{\circ} \mathrm{E}$. This is a manifestation of the competition 

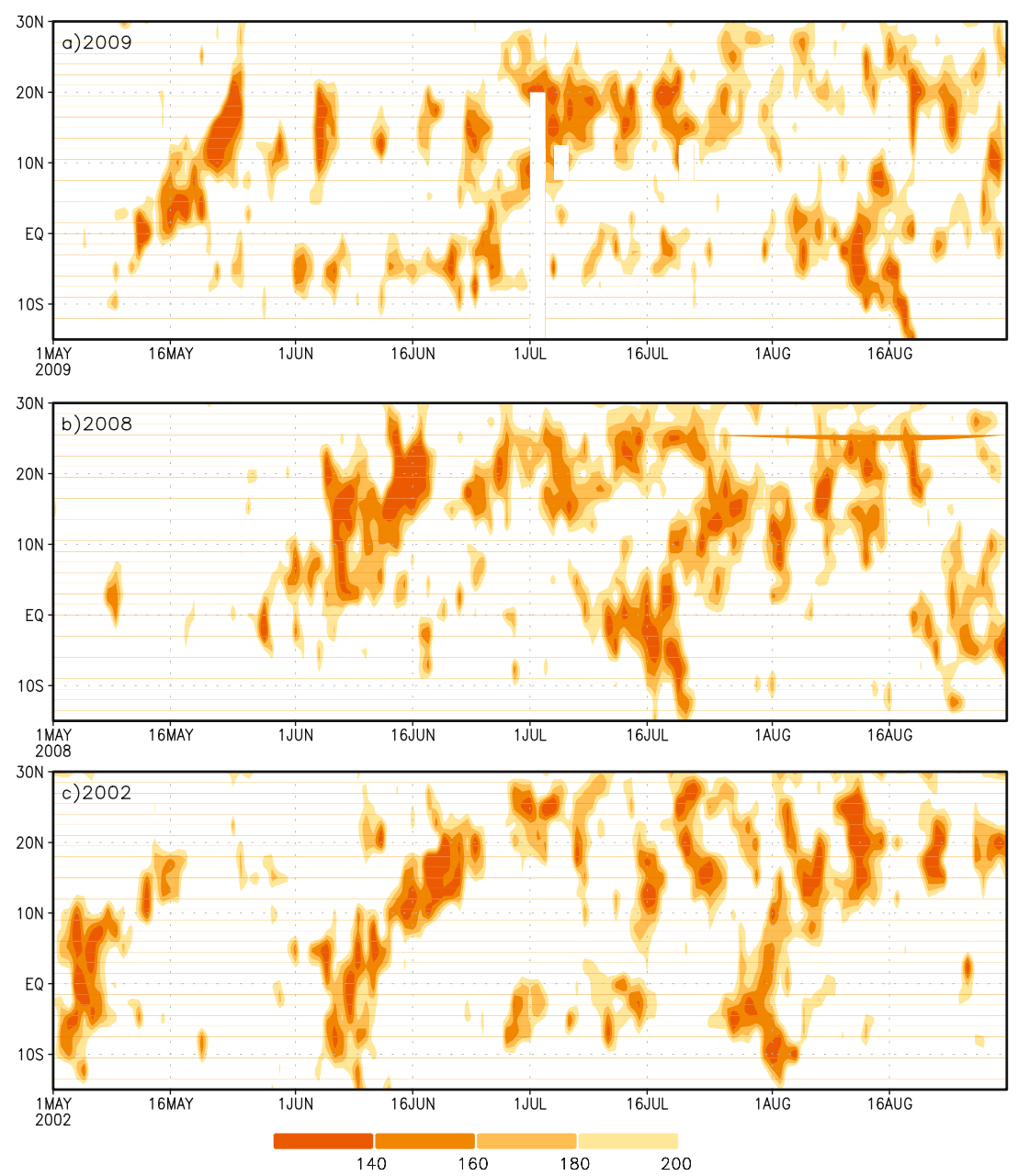

Figure 6. Daily variation of latitudinal belt with low $\operatorname{OLR}\left(\mathrm{Wm}^{-2}\right)$ at $85^{\circ} \mathrm{E}$ for the period 1 May to 31 August in (a) 2009 , (b) 2008, and (c) 2002 .

between the TCZ over the Bay and that over the eastern part of the equatorial region. The OLR anomaly pattern for June 2009 (figure 9a) also indicates that convection is enhanced over the eastern and central equatorial Indian Ocean and suppressed over a large part of the rest of the region including the entire Indian region and western equatorial Indian Ocean. Thus, it appears that, in June 2009, the convection over the central and eastern parts of the equatorial Indian Ocean was far more successful in the competition with the convection over the Bay than in most other years such as 2008. We consider next whether this unusual behaviour of the monsoon can be attributed to the negative phases of ENSO and EQUINOO.

\subsection{Impact of ENSO and EQUINOO}

Given the relationship of the monsoon with ENSO it has been suggested that the development of El Niño in the Pacific in June 2009 could have led to the large deficit in the Indian monsoon. However, note that the enhancement of convection over the central Pacific characteristic of El Niño (figure 9b), is not seen in the OLR anomaly pattern for June 2009 (figure 9a). Neither is the important effect of El Niño, viz., suppression of convection over the eastern equatorial Indian Ocean, seen in the OLR anomaly pattern of June 2009. Thus we cannot attribute the deficit rainfall over the Indian region in June 2009 to El Niño.

It is seen in figure 9(c) that the impact of a negative phase of EQUINOO in June is suppression of convection over the western equatorial Indian Ocean, Arabian Sea and the Indian region, while the convection is enhanced over EEIO and a large part of the Bay. The pattern of OLR anomaly of June 2009 is rather similar to that expected from an impact of negative EQWIN, except for the observed suppression of convection over a large part of the bay.

Gadgil et al $(2003,2004)$ have shown that the unprecedented drought in July 2002 was associated with an unfavourable ENSO and a strong negative EQUINOO. In July 2002, which was also characterized by negative phases of EQUINOO as well as 

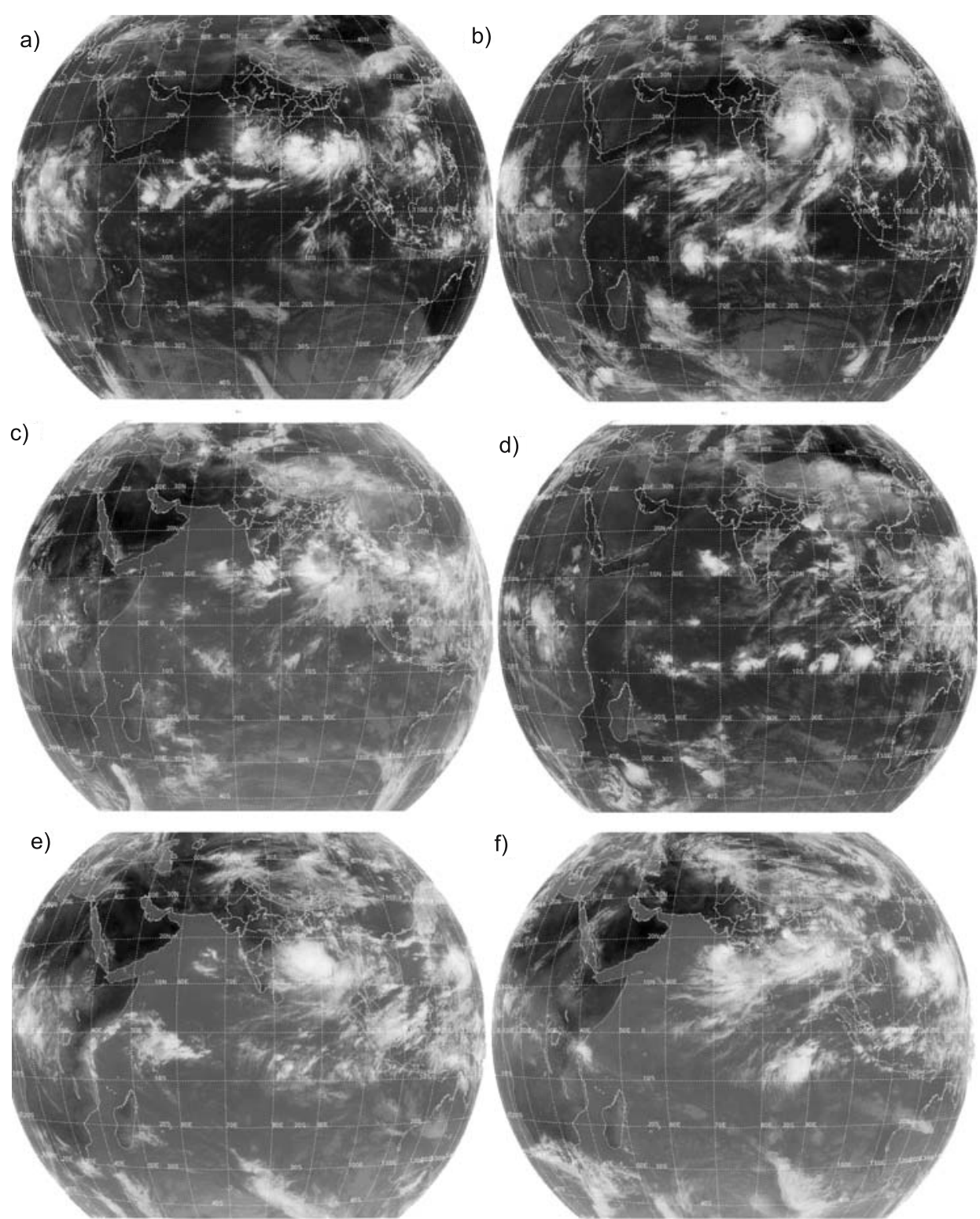

Figure 7. INSAT IR imagery for (a) 22 May 2009 at $0200 \mathrm{~h}$, (b) 25 May 2009 at $0200 \mathrm{~h}$, (c) 30 May 2009 at $1230 \mathrm{~h}$, (d) 1 June 2009 at $0200 \mathrm{~h}$, (e) 4 June 2009 at $0930 \mathrm{~h}$, and (f) 6 June 2009 at $1000 \mathrm{~h}$.

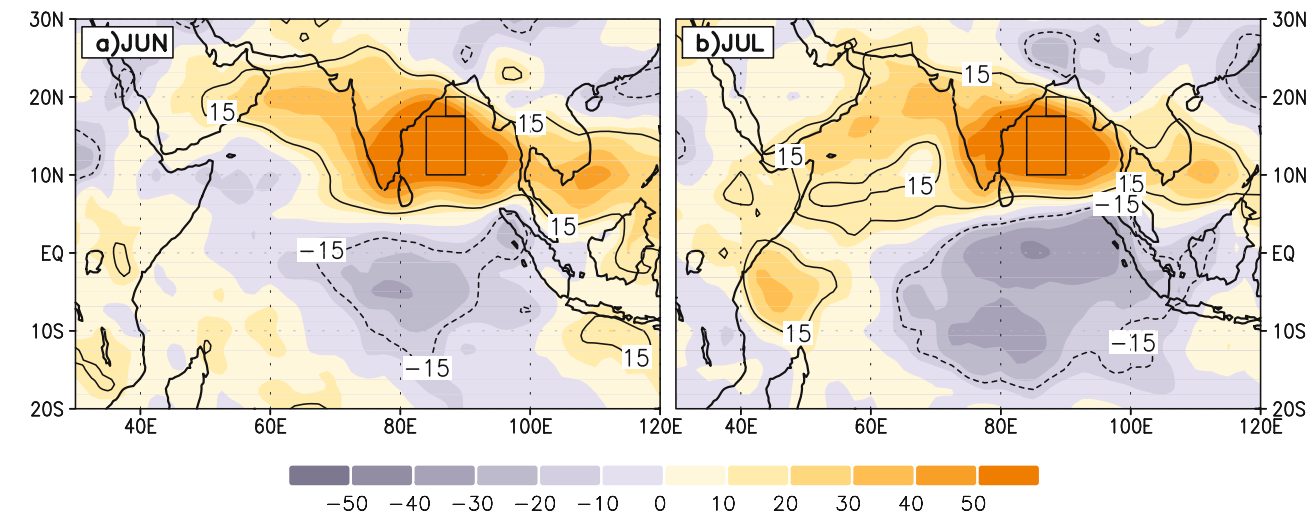

Figure 8. The correlation $(\times 100)$ of pentad mean OLR with the pentad OLR averaged over the Bay (region shown) for (a) June and (b) July. 

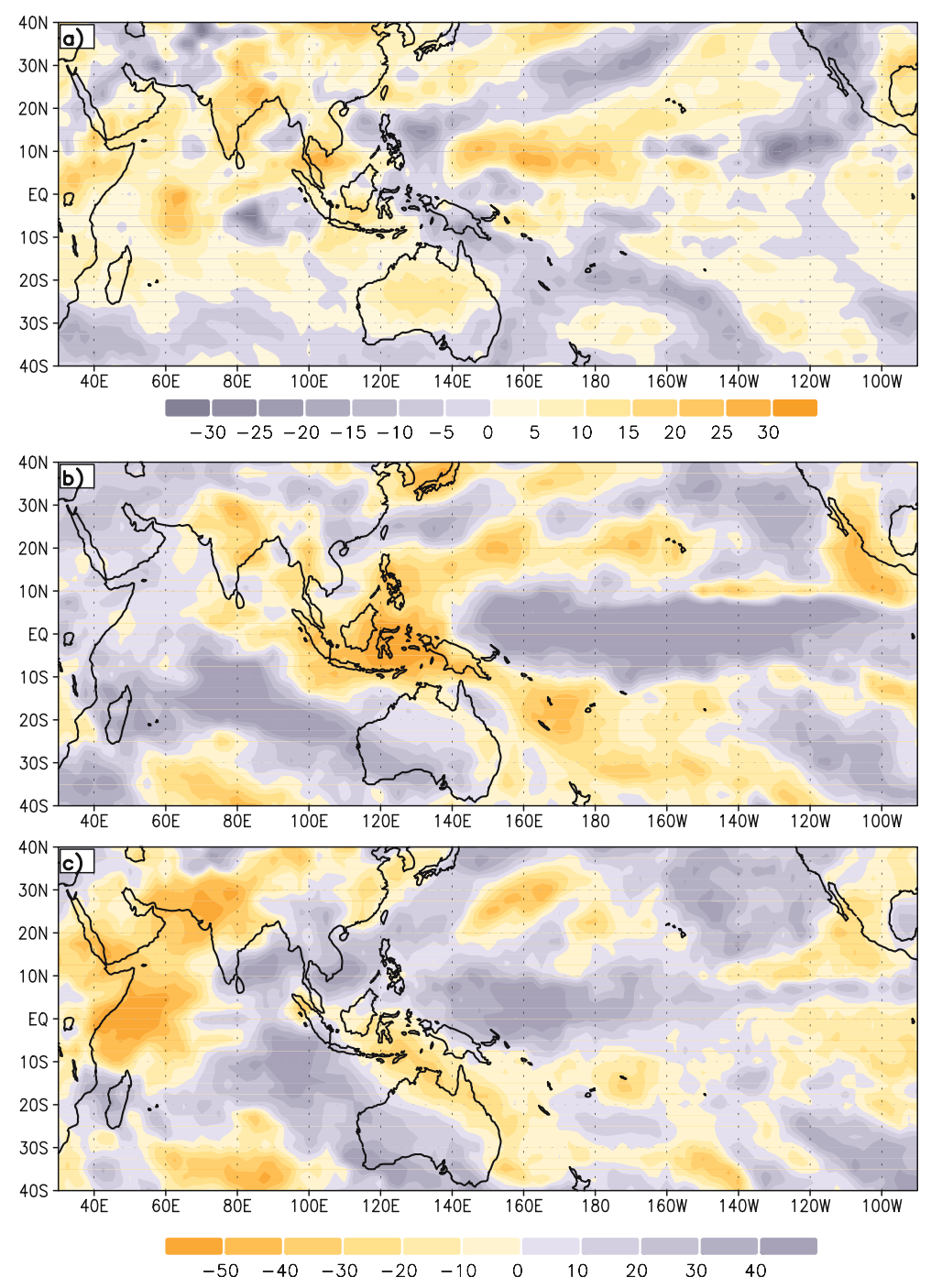

Figure 9. The OLR anomaly $\left(\mathrm{Wm}^{-2}\right)$ pattern for June 2009, (b) the correlation of the ENSO index with OLR for the month of June, and (c) the correlation of the EQWIN with OLR for the month of June.

ENSO, the magnitude of the anomaly for all-India rainfall was very large and comparable to that of June 2009. However, the magnitudes of the ENSO index and EQWIN were not as large in June 2009 as in 2002 (figure 5). Also, the most prominent feature of the variation over the Bay in June 2002 was a northward propagation from 5 to 24 June (figure 6) associated with the advance of the monsoon, whereas in the first three weeks of June 2009, there were no such propagations. Thus it appears that we cannot understand the aberrant behaviour of the monsoon in 2009 over the Bay either in terms of impact of ENSO or EQUINOO. Since the convection over the eastern part of the equatorial Indian Ocean in June 2009 appeared to be far more successful in the competition with the convection over the Bay than in most other years, we explore next, whether the sea surface temperature (SST) pattern of June 2009 rendered the equatorial Indian Ocean more favourable than the Bay.

\subsection{The culprit: Unusual SST pattern}

The evolution of the SST of the Bay (region shown in figure 8) and the EEIO as well as the difference between the SST of the EEIO and the Bay, based on Reynolds' SST data, for the years 2009, 1995 and 2008 and the climatological mean and TMI data for 2008 and 2009 are shown in figure 10(a). The evolution of the TMI SST is seen to be very similar to that of Reynolds' SST. The SST of the Bay is sensitive to atmospheric fluxes and decreases sharply during convective events (Premkumar et al 2000). The cooling of the Bay due to the severe cyclone Nargis in April 2008 and the cyclone Aila in May 2009 is clearly seen in the TMI SST evolution in figure 10(a). Under cloud free skies after each convective events the SST of the Bay increases. For example, it is seen that the Bay SST increases to climatological values by the end of May in 2008. On the other hand, the SST of EEIO 

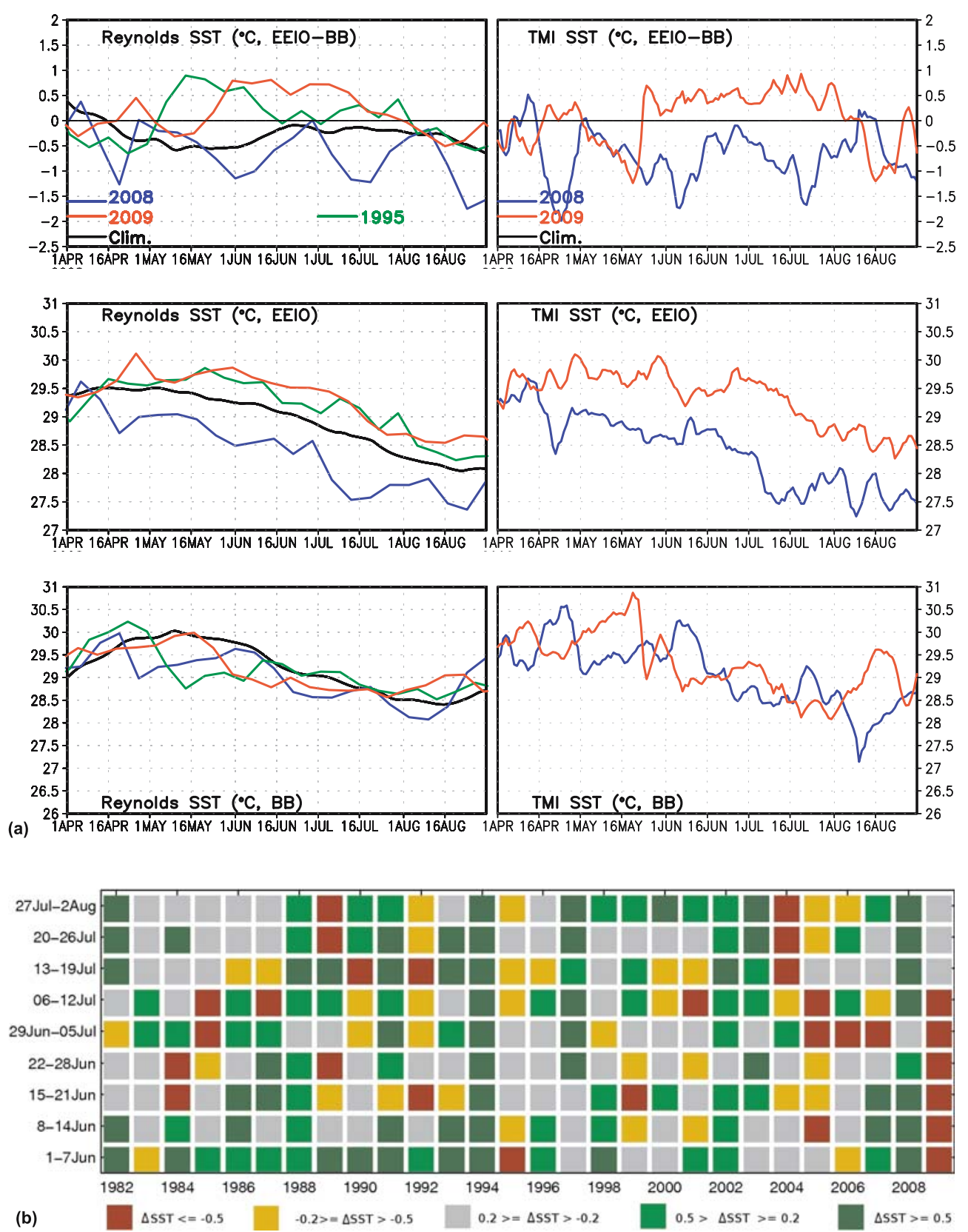

Figure 10. (a) Time series of $\mathrm{SST}\left({ }^{\circ} \mathrm{C}\right)$ averaged over the BB (region shown in figure 8), EEIO and the difference in SST between EEIO and BB. Weekly mean Reynolds' SST time series for 1995, 2008 and 2009 and climatology are shown in the left side panels and daily mean TMI SST for these years are shown in the right side panels. (b) Frequency of different values of the difference in SST between EEIO and the Bay for each week in June-July for the years.

changes slowly over the season, except in years in which positive IOD events develop during which the thermocline is relatively shallow.

Note that climatologically, the Bay is much warmer than EEIO during mid-May to mid-June, i.e., in the period in which onset occurs over Kerala and the monsoon advances across the Indian peninsula. During June 2009, the SST of the EEIO was higher than climatology by at least $0.5^{\circ} \mathrm{C}$ (i.e., around $29.5^{\circ} \mathrm{C}$ or higher), while the SST of the Bay was cooler than climatology (varying between $28.5^{\circ}$ and $29^{\circ} \mathrm{C}$ ). Thus there was a reversal of the SST gradient between the Bay and EEIO in June 2009. The variation of the SST for 2008 is also depicted in figure 10(a) since it turns out that while the EEIO during June 2009 was the warmest, it was the coldest in June-July 2008. The difference in the SSTs, i.e., EEIO - BB, is positive and highest for 2009; it is negative and of almost the largest magnitude for 2008.

We suggest that in June 2009, the high temperature of the eastern equatorial Indian Ocean relative to that over the Bay, has given an edge to the TCZ over the equatorial Indian Ocean in competition 

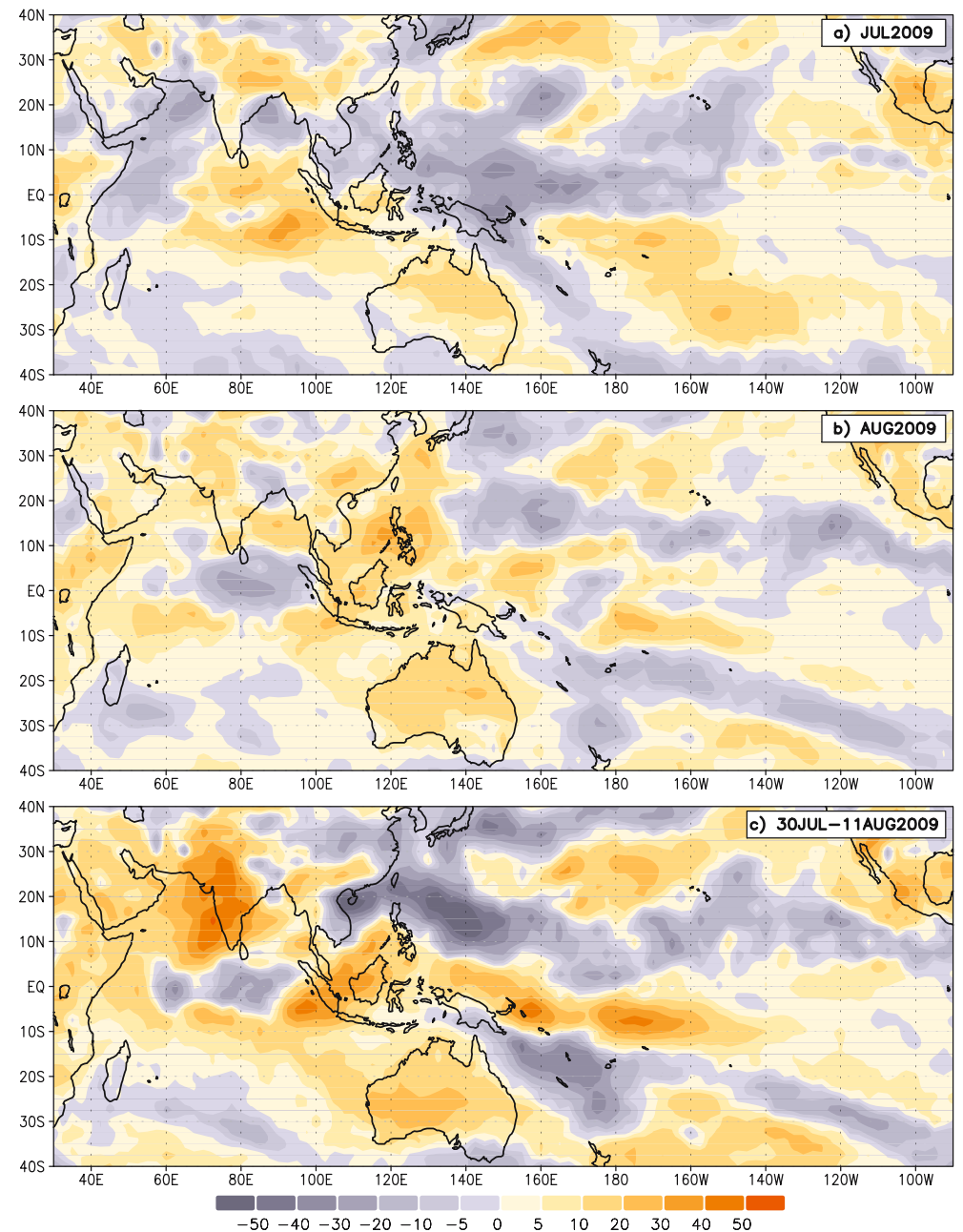

Figure 11. OLR anomaly $\left(\mathrm{Wm}^{-2}\right)$ for (a) July 2009, (b) August 2009, and (c) the break monsoon in the period 30 July-11 August 2009.

with the TCZ north of $10^{\circ} \mathrm{N}$ over the Bay. The TCZ/cloud systems over the Bay are, therefore, not sustained for longer than 3-4 days. No low pressure systems have been generated over the head Bay and the westward propagation across the monsoon zone, which is the characteristic of the onset phase of the monsoon, has not occurred.

Such a reversal of the SST gradient between the Bay and the equatorial Indian Ocean in the first fortnight of June, is rarely observed. This is clear from the frequency of the occurrence of different values of the difference between the values of the SST of EEIO and the Bay, for each 7-day period during 1 June-31 July for each year during 1982-2009, shown in figure 10(b). It may be noted that, in the first week of June, the Bay was cooler than the EEIO by more than $0.2^{\circ} \mathrm{C}$ in 4 years out of 28 years and, of these, by more than $0.5^{\circ} \mathrm{C}$ in only two years (1995 and 2009). The only year in which an adverse SST gradient occurred continuously from 1 June till the end of July is 2009. However, the magnitude of this gradient decreased considerably after the second week of July. On the other hand, the Bay was warmer than EEIO in the first week of June, by $0.2^{\circ} \mathrm{C}$ in 18 years and of these, by more than $0.5^{\circ} \mathrm{C}$ in 9 years. There is a marked change in the frequency of cases associated with positive and negative SST gradient between EEIO and the Bay by the third week of June. Thus the number of years with the Bay cooler than EEIO by at least $0.2^{\circ} \mathrm{C}$ more than doubled (from 4 to 9) while the number of years with the Bay warmer than EEIO is almost halved (from 18 to 10). This is a consequence of the decrease in SST of the Bay due to strong convection associated with the advance of the monsoon. For four weeks from 21 June, the chance that the SST gradient $>0.2^{\circ} \mathrm{C}$ is almost equal to that of the SST gradient $<-0.2^{\circ} \mathrm{C}$.

Thus the adverse SST gradient observed in 2009 is rather exceptional only for the first three weeks of June (figure 10b), In 1995, the only other year in which the Bay was cooler than EEIO for several days in June convection over the Bay was also 
suppressed and the all-India rainfall for June 1995 was $24 \%$ below the normal (Parthasarathy et al 1994.) The OLR anomaly patterns for this period in June 1995 is rather similar to that for 1-24 June 2009 with suppressed convection over the Indian region and adjoining Bay and enhanced convection over eastern and central equatorial Indian Ocean.

\section{The monsoon of 2009 during the peak monsoon months of July and August}

The monsoon revived from the last week of June and the all-India rainfall in July was $95 \%$ of normal (http://www.imd.gov.in). However, there was a large deficit of $27 \%$ in the all-India rainfall in August. We next attempt to understand the partial recovery of the monsoon in July and the large deficit in August. As pointed out, from about 20 June until the end of July, several years are characterized by EEIO slightly warmer than BB (figure 10b). Thus the gradient of SST between the Bay and the EEIO in this period in 2009 cannot be considered to be exceptional and we do not expect it to have played a role in the convection over the Bay and the Indian region after the third week of June. We note that subsequent to the first three weeks of June, northward propagations did occur. We consider next the usual suspects - ENSO and EQUINOO.

We expect ENSO to have had an impact since the El Niño over the Pacific had developed by July and anomalous convection over the equatorial central Pacific was seen in July and August. Note that the suppression of convection over EEIO which is associated with El Niño was clearly seen in the OLR anomaly patterns of July and August (figure 11a, b), whereas convection over EEIO was not suppressed in June (figure 9a). A break occurred during 30 July-11 August. The OLR anomaly pattern for this break shows suppression of convection over the Indian region (except the northeast), the Bay, the Arabian Sea as well as over EEIO (figure 11c). Convection is enhanced over the central and eastern equatorial ocean (i.e., region $\left.70^{\circ}-100^{\circ} \mathrm{E}, 0^{\circ}-10^{\circ} \mathrm{N}\right)$. Comparison with the composite OLR anomaly pattern of the break (Rajeevan et al 2008) shows that unlike in the composite, convection was suppressed over EEIO in this break. Revival from this break occurred with a northward propagation of the equatorial cloud band during 8 to 18 August (figure 6). The OLR anomaly for August was similar to that of the break being characterized by suppression of convection over EEIO and enhancement of convection over the central equatorial Indian Ocean. Positive anomaly in convection over the central equatorial
Indian Ocean is expected to be associated with suppression of convection over the Bay and the Indian region.

While the phase of EQUINOO was negative in June with enhanced convection over EEIO and suppressed convection over WEIO (figure 9a), it became positive in July with enhanced convection over WEIO. In association with the positive phase of EQUINOO, convection was also enhanced over the Arabian Sea and the Bay of Bengal and over the Indian region, implying a partial recovery of the monsoon. The convection over WEIO was again suppressed in August and enhanced over the central and part of the eastern equatorial ocean leading to a negative phase of EQUINOO. We need to understand why the convection over WEIO was enhanced in July and suppressed again in August.

The mean OLR patterns (figure 3c) show that convection occurs over EEIO as well as WEIO during June-August. This suggests that climatologically both the regions are favourable for convection in this period. In fact, in positive (negative) phases of the EQUINOO, the propensity of convection over WEIO (EEIO) is higher than that over EEIO (WEIO); but the convection over EEIO (WEIO) is generally not completely suppressed (Francis et al 2007). The negative correlation of OLR of EEIO with that of WEIO suggests that a suppression over EEIO would be associated with the enhancement of convection over WEIO. We suggest that the suppression of convection over EEIO in July in association with the El Niño, led to the enhancement of convection over WEIO. Once the convection is enhanced over WEIO, easterly anomalies of zonal wind appear and enhance the convergence into that region; the convection can be sustained through this positive feedback (Francis et al 2007). However, in 2009, the convection over WEIO was again suppressed in August although the convection over EEIO continued to be suppressed. We need to understand why the convection over WEIO not sustained in August.

We first explored whether the nature of the equatorial SST distribution could have led to the suppression of convection of WEIO in August. The variation of the OLR anomaly over and SST of WEIO, CEIO and EEIO during JJA 2009 (figure 12a) shows that the SST of the WEIO decreased considerably during the deep convection episode in July. If this decrease was associated with cooling of the entire region below the threshold of $28^{\circ} \mathrm{C}$, convection would be suppressed. However, we find that while the fraction of the area within the WEIO, for which the SST was above the threshold for deep convection, did decrease substantially, it did not go to zero (figure $12 \mathrm{~b}$ ). Hence it appears that the SST of WEIO was not a limiting factor for convection over the WEIO in August 

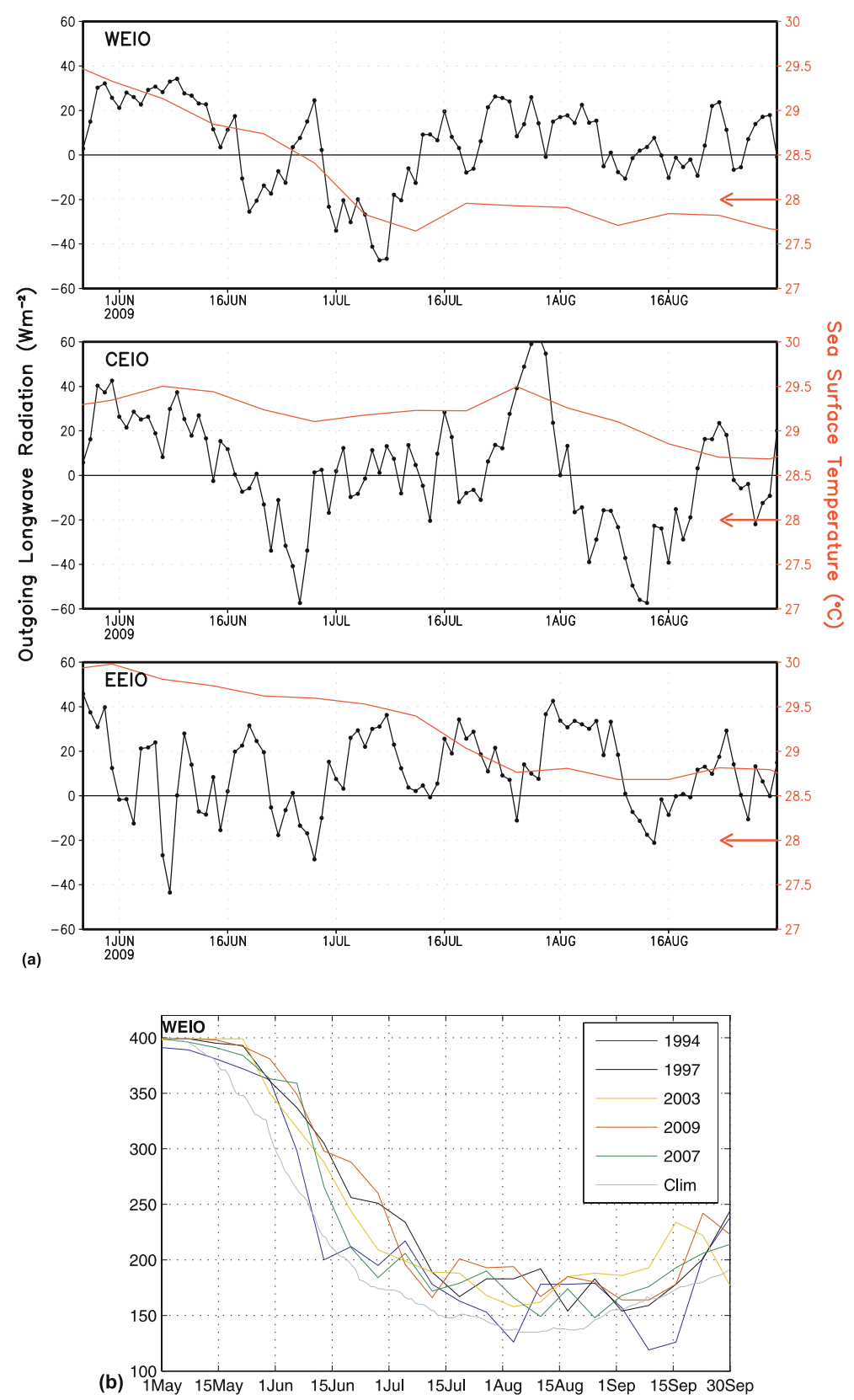

Figure 12. (a) Variation of the OLR anomaly $\left(\mathrm{Wm}^{-2}\right)$ over and SST $\left({ }^{\circ} \mathrm{C}\right.$; Reynolds) in the WEIO, CEIO and EEIO. (b) Number of grids within WEIO in which SST $\geq 28^{\circ} \mathrm{C}$ for 1994, 1997, 2003, 2007 and 2009.

2009. The other possible factor that could have led to the shift of the convection from over WEIO in July to over CEIO in August, is the large SST gradient between the CEIO and the WEIO, which had cooled considerably. However, we find that such a gradient also existed in seasons such as 1994 during which convection was sustained over WEIO throughout the season. So, the shift of the convection to CEIO in August cannot be attributed to the CEIO being much warmer than WEIO either.

Given the discernible impact of the El Niño in suppression of convection over EEIO in July and
August, we next consider the likely impact of the El Niño on convection over WEIO. The composite OLR anomaly patterns for July and August of all the El Niño events from 1982 (except that of 2009) are shown in figure 13. As expected, a prominent feature of the composites is the suppression of convection over the EEIO. It is interesting that enhanced convection over WEIO also seen in the El Niño composite of OLR anomaly for July (figure 13a). It is seen from the OLR anomaly pattern that the El Niño was well established over the central-eastern equatorial Pacific by August 2009. The El Niño composite pattern for August 

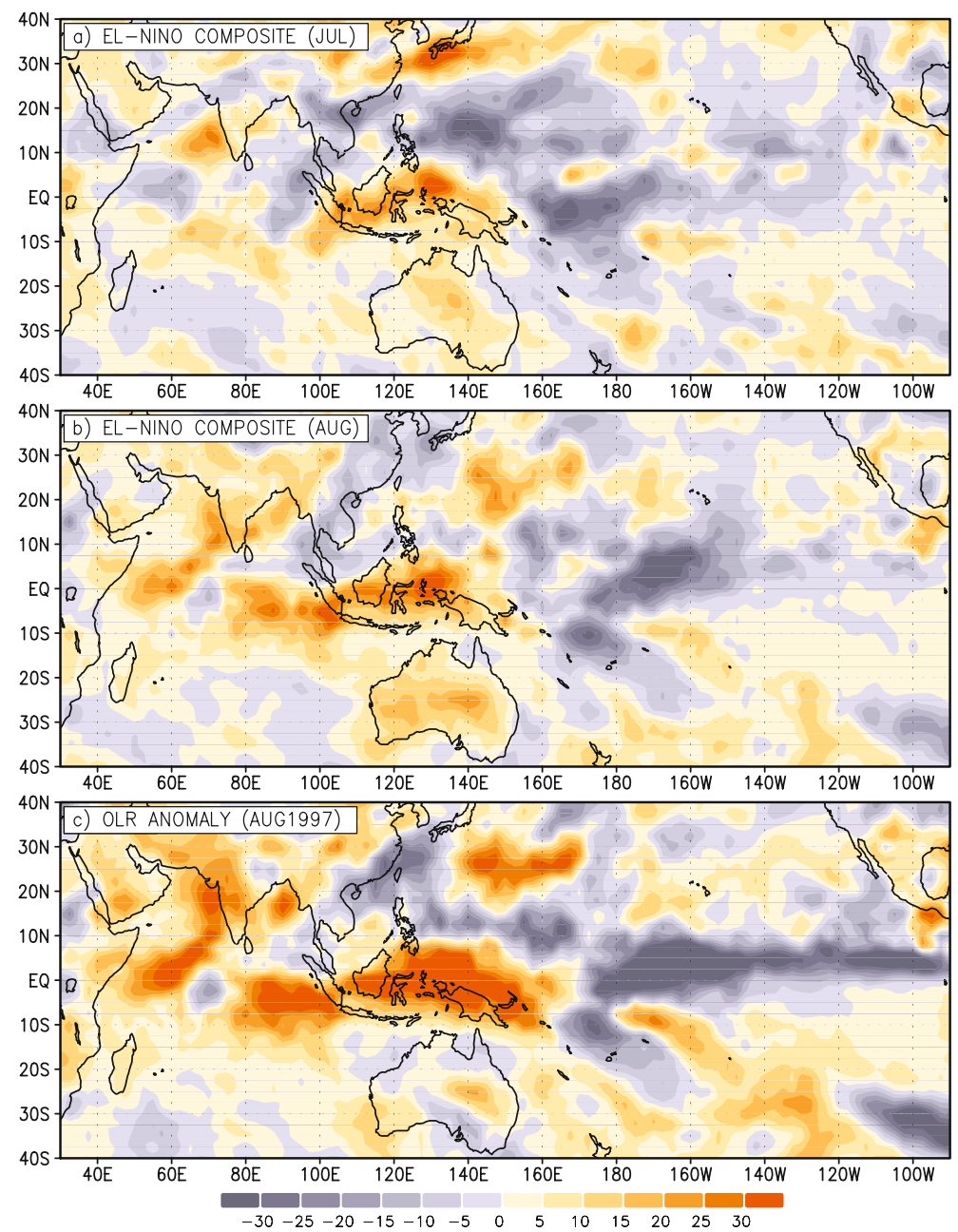

Figure 13. (a) Composites of the July OLR anomaly pattern for the El Niño events (1982, 1987, 1997, 2002, 2006), (b) same as (a), but for August, and (c) OLR anomaly $\left(\mathrm{Wm}^{-2}\right)$ pattern for August 1997.

(figure 13b) shows a clear suppression of convection over the WEIO. In fact, even in 1997, in which one of the strongest positive IOD event occurred (so one would have expected sustained convection over WEIO), the convection over the WEIO was suppressed in August (figure 13c). The composite pattern of August OLR anomaly (figure 13b) suggests that the convection over the CEIO is slightly enhanced in association with El Niño. Consistent with the El Niño composite for August, in August 2009, the convection over the WEIO and EEIO remained suppressed, while it was enhanced over the CEIO.

\section{Summary and concluding remarks}

The role of ENSO and EQUINOO in the interannual variation of the monsoon is well known. We suggest that, in addition, the unusual SST pattern of the equatorial Indian Ocean played an important role in the anomalous rainfall over the Indian region during June of 2009. In June 2009, El Niño was developing and the phase of EQUINOO was unfavourable with enhancement of convection over the eastern (EEIO) and central (CEIO) equatorial Indian Ocean and suppression over the western part (WEIO). This study has shown that an additional unfavourable factor, viz., the Bay being much cooler than EEIO, which led to a suppression of convection over the Bay and the Indian region, could have contributed to the massive deficit in the rainfall in June 2009. We must emphasize that the occurrence of such a gradient in the first two weeks of June, is a rather rare event. On the other hand, the occurrences of the extreme phases of ENSO and EQUINOO which are known to have a large impact on the interannual variation of the monsoon are by no means rare. So while this factor seems to have played a key role in disrupting the advance of the monsoon in June 2009, we do not expect it to be a critical factor in most of the years. In fact, the severe drought of the summer monsoon of 2009 has also 


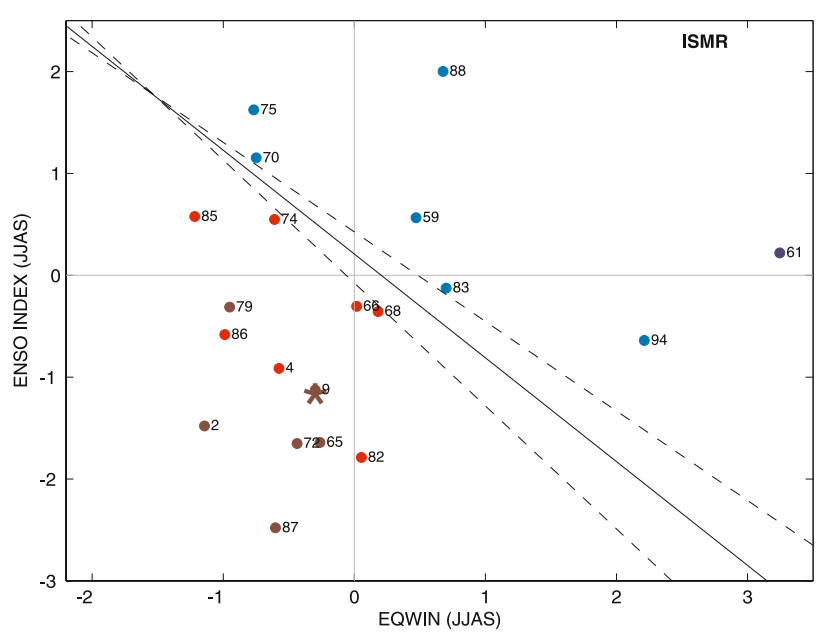

Figure 14. Extremes of all India monsoon rainfall (ISMR) for 1958-2009 plotted in the phase plane of ENSO index and EQWIN. The red symbols are for droughts, i.e., ISMR anomaly $<-1$ standard deviation and dark red for severe droughts, i.e., $<-1.5$ standard deviation; blue symbols are for excess monsoon rainfall, i.e., ISMR anomaly $>1$ standard deviation and dark blue for large excess, i.e., ISMR anomaly $>1.5$ standard deviation.

occurred in association with unfavourable phases of both ENSO and EQUINOO (figure 14).

We have noted that during June 2009, when the phase of EQUINOO was unfavourable, WEIO was not much colder than EEIO and convection appeared over WEIO in the weak spells of convection over EEIO. In July, the convection over EEIO was suppressed (in association with El Niño which had developed) and that over WEIO was enhanced, and the phase of EQUINOO became favourable. Thus despite the El Niño, the rainfall was close to the mean in July. As in the El Niño composite OLR anomaly pattern for August, the August 2009 OLR anomaly pattern shows suppression of convection over EEIO as well as WEIO. However, the convection over CEIO and eastern equatorial Indian Ocean north of the equator was much enhanced in August 2009. In association with this enhanced convection over the central equatorial Indian Ocean, a large deficit occurred in the August rainfall.

In short, we suggest that the large deficit in rainfall over the Indian region in June can be attributed to the exceptional adverse SST gradient between the Bay and the eastern and central equatorial Indian Ocean, which led to the enhancement of convection over this part of the equatorial Indian Ocean and suppression of convection over the Bay. The normal rainfall in July is associated with enhancement of convection over the western equatorial Indian Ocean characteristic of a positive phase of the EQUINOO which we believe occurred because of the suppression of convection over EEIO by the El Niño. It appears that the suppression of the convection over WEIO in August can also be attributed to the El Niño. However, we do not understand why the convection was so intense over CEIO in August.

So far we have considered only the data of OLR and SST. Clearly the different hypotheses proposed here have to be tested with further analysis of data particularly circulation. For example, it is necessary to analyze the nature of the impact of the El Niño on the divergence fields to elucidate the teleconnection with the convection over equatorial Indian ocean. Modelling studies are also required to test the hypotheses proposed. If the hypothesis we propose for the massive deficit in June is proven true, then it would be important to closely monitor, and attempt prediction of the SST of the EEIO and the Bay, particularly in years in which the EEIO SST is warmer than average in the beginning of the monsoon season.

Given the important role played by EQUINOO in the interannual variation of the Indian summer monsoon, it is important to gain deeper insight into the phenomenon with further analysis of data and modeling studies. For this, prediction of the SST and depth of the thermocline of EEIO and WEIO is a prerequisite. Thus, in addition to prediction of the ENSO, prediction and monitoring the SST over the critical regions, viz., WEIO, EEIO and the Bay appears to be critical in the prediction of monsoon.

\section{Acknowledgements}

We are grateful to Profs J Srinivasan, P N Vinayachandran, G S Bhat and Ravi Nanjundiah of CAOS, IISc, for substantial inputs in many discussions during the endeavour to understand the monsoon of 2009. We also benefited from discussions with Dr Satish Shetye, and Dr D Shankar of NIO and Dr Sateesh Shenoi of INCOIS. It is a pleasure to specially acknowledge the detailed comments, suggestions of Prof. Mark Cane of Columbia University, New York and Dr M Rajeevan of NARL, ISRO which contributed to the substantial improvement of the paper. This work was supported by INCOIS through the project F/INCOIS/R\&D-01-2007.

\section{References}

Bhat G S 2006 The Indian drought of 2002 - a subseasonal phenomenon?; Quart. J. Roy. Meteor. Soc. 132 2583-2602.

Ding Y and Sikka D R 2006 Synoptic systems and weather; The Asian Monsoon (ed.) Wang B, Springer-Verlag, 131-201.

Ding Q and Wang B 2007 Intraseasonal teleconnection between the Eurasian wave train and Indian summer monsoon; J. Climate 20 3751-3767. 
Francis P A, Gadgil S and Vinayachandran P N 2007 Triggering of positive dipole by severe cyclones over the Bay of Bengal; Tellus $-A \mathbf{5 9} 461-475$.

Francis P A and Gadgil S 2009 The aberrant behaviour of the Indian monsoon in June 2009; Curr. Sci. 97(9) 1291-1295.

Gadgil S 2003 The Indian Monsoon and its variability; Ann. Rev. Earth. Planet. Sci. 31 429-467.

Gadgil Sulochana and Joseph P V 2003 On breaks of the Indian monsoon; Proc. Indian Acad. Sci. (Earth Planet. Sci.) 112 529-558.

Gadgil S, Joseph P V and Joshi N V 1984 Oceanatmosphere coupling over monsoonal regions; Nature 312 141-143.

Gadgil S, Vinayachandran P N and Francis P A 2003 Droughts of Indian summer monsoon: Role of clouds over the Indian Ocean; Curr. Sci. 85 1713-1719.

Gadgil S, Vinayachandran P N, Francis P A and Gadgil S 2004 Extremes of the Indian summer monsoon rainfall, ENSO and the equatorial Indian Ocean Oscillation; Geophys. Res. Lett. 31(L1) 2213, doi: 10.1029/2004GL019733.

Gadgil S, Rajeevan M and Nanjundiah R 2005 Monsoon prediction - Why yet another failure? Curr. Sci. 88 1389-1400.

Graham N E and Barnett T P 1987 Sea surface temperature, surface wind divergence and convection over tropical oceans; Science $\mathbf{2 3 8}$ 657-659.

Ihara C, Kushnir Y, Cane M A and De la Peña V 2007 Indian summer monsoon rainfall and its link with ENSO and the Indian Ocean indices; Int. J. Climatol. $\mathbf{2 7}$ 179-187.

Ihara C, Kushnir Y, Cane M A and Kaplan A 2008 Timing of El Niño-related warming and Indian summer monsoon rainfall; J. Climate 21(11) 2711-2719.

Joseph P V and Srinivasan J 1999 Rossby waves in May and the Indian Summer Monsoon Rainfall; Tellus 51A 854-864.

Kalnay E, Kanamitsu M, Kistler R, Collins W, Deaven D, Gandin L, Iredell M, Saha S, White G, Woollen J, Zhu Y, Leetmaa A, Reynolds R, Chelliah M, Ebisuzaki W, Higgins W, Janowiak J, Mo K, Ropelewski C, Wang J, Jenne R and Joseph D 1996 The NCEP/NCAR 40-Year Reanalysis Project; Bull. Amer. Meteor. Soc. 77 437-471.

Kripalani R H, Kulkarni A A and Singh S V 1997 Association of the Indian summer monsoon with the northern hemisphere mid-latitude circulation; Int. J. Climatol. 17 1055-1067.

Krishnamurti T N, Bedi H S and Subramaniam M 1989 The summer monsoon of 1987; J. Climate 2 321-340.

Krishnamurti T N, Thomas A, Simon A and Kumar V 2009 Desert air incursions, an overlooked aspect, for the dry spells of Indian summer monsoon (sumbitted to J. Atmos. Sci.).

Krishna Kumar K, Rajagopalan B, Hoerting M, Bates G and Cane M 2006 Unraveling the mystery of Indian monsoon failure during El-Niño; Science 314 115-119.
Liebmann B and Smith C A 1996 Description of a complete (interpolated) outgoing longwave radiation dataset; Bull. Amer. Meteor. Soc. 77 1275-1277.

Nanjundiah R 2009 A quick-look assessment of forecasts for the Indian summer monsoon rainfall in 2009; 2009-AS-2, CAOS Technical Report, Centre for Atmospheric and Oceanic Sciences, Indian Institute of Science, Bangalore.

Pant G B and Parthasarathy B 1981 Some aspects of an association between the southern oscillation and Indian summer monsoon; Arch. Meteorol. Geophys. Biokl. 29 $245-251$.

Parthasarathy B, Munot A A and Kothawale D R 1994 All India monthly and seasonal rainfall series 1871-1993; Theor. Appl. Climatol 49 217-224.

Premkumar K, Ravichandran M, Kalsi S R, Sengupta D and Gadgil S 2000 First results from a new observational system over the Indian seas; Curr. Sci. 78 323-331.

Rajeevan M 1993 Upper tropospheric circulation and thermal anomalies over central Asia associated with major droughts and floods in India; Curr. Sci. 64 244-247.

Rajeevan M, Sulochana Gadgil and Jyoti Bhate 2008 Active and break spells of the Indian monsoon, NCC Research Report No. 7/2008, National Climate Centre, India Meteorological Department (available at http:/www.imdpune.gov.in).

Rajeevan M, Gadgil S and Bhate J 2010 Active and break spells of the Indian summer monsoon; J. Earth Syst. Sci. 119(3) 229-247.

Raman C R V and Rao Y P 1981 Blocking highs over Asia and monsoon droughts over India; Nature 289 271-273.

Ramaswami C 1958 A preliminary study of the behavior of the Indian southwest monsoon in relation to the westerly jet stream; Geophysica 6 455-477.

Rasmusson E M and Carpenter T H 1983 The relationship between eastern equatorial Pacific sea surface temperatures and rainfall over India and Sri Lanka; Mon. Wea. Rev. 111 517-528.

Reynolds R W, Rayner N A, Smith T M, Stokes D C and Wang W Q 2002 An improved in situ and satellite SST analysis for climate; J. Climate 15 1609-1625.

Sikka D R 1980 Some aspects of the large-scale fluctuations of summer monsoon rainfall over India in relation to fluctuations in the planetary and regional scale circulation parameters; Proc. Indian Acad. Sci. (Earth Planet. Sci.) 89 179-195.

Sikka D R and Gadgil S 1980 On the maximum cloud zone and the ITCZ over India longitude during the southwest monsoon; Mon. Weather Rev. 108 1122-1135.

Wang B, Lee J-Y, Kang I-S, Shukla J, Kug J-S, Kumar A, Schemm J, Luo J-J, Yamagata T and Park C-K 2008 How accurately do coupled climate models predict the Asian-Australian monsoon interannual variability? Climate Dyn. 30 605-619, doi: 10.1007/s00382-007-0310-5.

Yasunari T 1987 Global structure of El Niño/Southern Oscillation. Part I. El Niño composites; J. Met. Soc. Japan 65 67-80. 